\title{
A Homologous Series of First-Row Transition-Metal Complexes of 2,2'-Bipyridine and their Ligand Radical Derivatives: Trends in Structure, Magnetism, and Bonding
}

\author{
Mark Irwin, ${ }^{\dagger}$ Laurence R. Doyle, $^{\dagger}$ Tobias Krämer, $^{\dagger}$ Radovan Herchel, $^{\ddagger}$ John E. McGrady, ${ }^{*}{ }^{\dagger}$ \\ and Jose M. Goicoechea ${ }^{*}, \dagger$ \\ ${ }^{\dagger}$ Department of Chemistry, Inorganic Chemistry Laboratory, University of Oxford, South Parks Road, Oxford OX1 3QR, U.K.
${ }^{\ddagger}$ Regional Centre of Advanced Technologies and Materials, Department of Inorganic Chemistry, Faculty of Science, Palacký
University, 17. listopadu 12, CZ-77146 Olomouc, Czech Republic
}

Supporting Information

ABSTRACT: The organometallic first-row transition-metal complexes $\left[\mathrm{M}\left(2,2^{\prime}\right.\right.$-bipy $\left.)(\mathrm{mes})_{2}\right](\mathrm{M}=\mathrm{Cr}$ (1), $\mathrm{Mn}$ (2), Co (4), $\mathrm{Ni}(5) ; 2,2^{\prime}$-bipy = 2,2' -bipyridine; mes = 2,4,6- $\mathrm{Me}_{3} \mathrm{C}_{6} \mathrm{H}_{2}$ ) were reacted with potassium and a suitable alkali-metal sequestering agent to yield salts of the anionic species $\left[\mathrm{M}\left(2,2^{\prime} \text {-bipy }\right)(\mathrm{mes})_{2}\right]^{-}$. The neutral parent compounds and their corresponding anionic congeners were characterized by single-crystal X-ray diffraction in $\left[\mathrm{Cr}\left(2,2^{\prime}\right.\right.$-bipy)(mes $\left.)_{2}\right] \cdot 1.5 \mathrm{C}_{6} \mathrm{H}_{6}, \quad\left[\mathrm{Mn}\left(2,2^{\prime}\right.\right.$-bipy $\left.)(\mathrm{mes})_{2}\right],\left[\mathrm{Co}\left(2,2^{\prime}\right.\right.$-bipy $)$ (mes) $\left.)_{2}\right]$ THF, [Ni(2,2'-bipy)(mes) $\left.)_{2}\right]$, [K(dibenzo-18-crown6) $\cdot \mathrm{THF}]\left[\mathrm{Cr}\left(2,2^{\prime}\right.\right.$-bipy $\left.)(\mathrm{mes})_{2}\right] \cdot 2 \mathrm{THF},[\mathrm{K}(18$-crown-6) $][\mathrm{Mn}$ $\left(2,2^{\prime}\right.$-bipy $\left.)(\mathrm{mes})_{2}\right] \cdot 2 \mathrm{THF}, \quad[\mathrm{K}(18$-crown-6)][Mn(2,2'-bipy)-

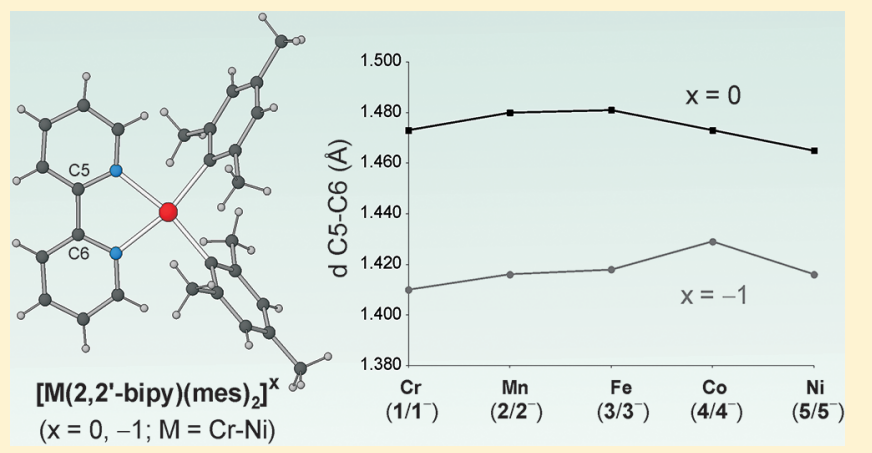
(mes $\left.)_{2}\right] \cdot 0.67 \mathrm{py} \cdot 0.67 \mathrm{tol}, \quad[\mathrm{K}(2,2,2$-crypt $)]\left[\mathrm{Co}\left(2,2^{\prime}\right.\right.$-bipy $)$ (mes $\left.)_{2}\right]$, and $[\mathrm{K}(2,2,2$-crypt $\left.)]\left[\mathrm{Ni}\left(2,2^{\prime} \text {-bipy }\right) \text { (mes) }\right)_{2}\right]$. These species, along with the previously reported neutral and anionic iron complexes $\left[\mathrm{Fe}\left(2,2^{\prime} \text {-bipy }\right)(\mathrm{mes})_{2}\right]^{0 /-}\left(3 / 3^{-}\right)$, form a homologous series of compounds which allow for an in-depth study of the interactions between metals and ligands. Single-crystal X-ray diffraction data, DFT calculations, and various spectroscopic and magnetic measurements indicate that the anionic complexes $\left(1^{-}-5^{-}\right)$can be best formulated as $\mathrm{M}$ (II) complexes of the $2,2^{\prime}$ bipyridyl radical anion. These findings complement recent studies which indicate that bond metric data from single-crystal X-ray diffraction may be employed as an important diagnostic tool in determining the oxidation states of bipyridyl ligands in transitionmetal complexes.

\section{INTRODUCTION}

The redox-active character of the bidentate ligand $2,2^{\prime}$ bipyridine (2,2'-bipy) has been well documented since early spectroscopic measurements demonstrated that it could be chemically reduced to yield metal salts of the $\pi$-radical monoanion $\left(2,2^{\prime}\right.$-bipy $\left.^{\bullet-}\right)$ or the diamagnetic dianion $\left(2,2^{\prime}\right.$ bipy $\left.{ }^{2-}\right) .{ }^{1-5}$ All three oxidation states of the ligand have been structurally characterized by single-crystal X-ray diffraction and show variations in bond metrics which are consistent with the occupation of an energetically low-lying $\pi$ orbital upon reduction. ${ }^{6-8}$ This orbital (the LUMO of neutral 2,2'-bipy; Figure 1a) has net antibonding character and nodes located between alternating $\mathrm{C}-\mathrm{N}$ and $\mathrm{C}-\mathrm{C}$ bonds. A comparison of the structure of neutral bipyridine with alkali-metal salts of the radical anion and dianion shows significant changes to $\mathrm{C}-\mathrm{C}$ and $\mathrm{C}-\mathrm{N}$ distances, indicative of the population of the aforementioned molecular orbital (Figure 1b). ${ }^{7}$ This can also be rationalized as a loss of aromaticity of neutral $2,2^{\prime}$-bipyridine to yield structures with localized double bonds such as those pictured in Figure 1c. The most pronounced change in bond distances is observed for the interpyridyl ring bond, which varies from approximately $1.49 \AA$ for the neutral ligand to 1.43 $\AA$ for $2,2^{\prime}$-bipy ${ }^{\bullet-}$ and finally to $1.39 \AA$ for $2,2^{\prime}$-bipy ${ }^{2-}$.

To date, there have been several reports of structurally authenticated complexes of bipyridyl radical anions and dianions with main-group elements, ${ }^{9}$ lanthanides, and actinides. ${ }^{10,11}$ In contrast, related "non-innocent" complexes of the transition metals in which the oxidation state of the metal and ligand have been determined unequivocally and proven to contain reduced forms of 2,2'-bipyridine are much rarer. To our knowledge, the first example of such a complex was $\left[(\mathrm{CO})_{4} \mathrm{Cr}\left(2,2^{\prime} \text {-bipy }\right)\right]^{-}$, where EPR and UV-vis spectroscopy as well as DFT calculations suggest formulation as a $\operatorname{Cr}(0)$ complex of the radical anion $2,2^{\prime}$-bipy ${ }^{\bullet-}{ }^{12}$ However, this anionic complex has never been characterized crystallographically. In contrast, there are several examples of crystallographically characterized transition-metal complexes

Received: July 20, 2012

Published: October 30, 2012 
a)
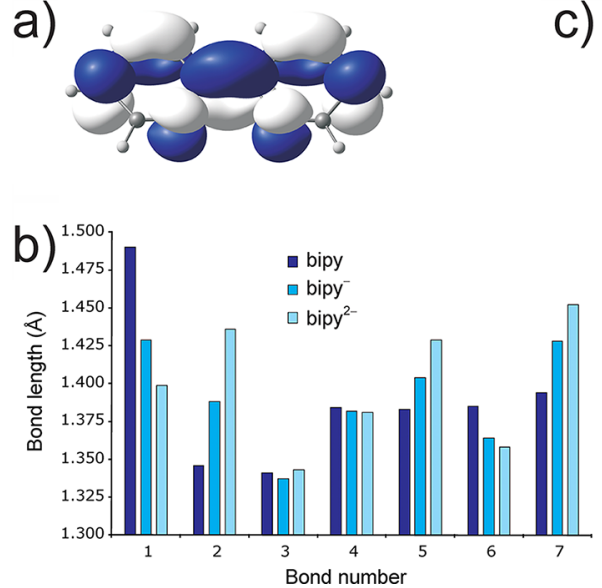

Figure 1. (a) LUMO of 2,2'-bipyridine. (b) Variations in interatomic bond distances for $2,2^{\prime}$-bipy ${ }^{x}(x=0,1-, 2-)$ as taken from ref 7 (bond numbering shown in (c)). (c) Lewis structures of the neutral, radical anionic, and diamagnetic dianionic forms of 2,2'-bipyridine.

of 2,2'-bipyridine where bond metric parameters strongly suggest the possibility of radical (or even dianionic) character to the ligand, although the compounds were not formulated as such. ${ }^{6,13,14}$ The principal reason such species have gone unidentified is that shifts in the interatomic distances within the bipyridyl moieties could, at least in principle, be rationalized in terms of extensive back-bonding from electron-rich metal centers to the bipyridine ligand. This mechanism would also effectively populate the LUMO of 2,2'-bipy and hence lead to a contraction of the $\mathrm{C}-\mathrm{C}$ bond linking the two rings. Recently, however, Wieghardt and co-workers have disputed this notion, arguing that the $\pi$-acceptor ability of $2,2^{\prime}$-bipyridine is negligible and that changes in bipyridyl bond metrics are an indicator of ligand oxidation state. ${ }^{15}$ The authors invoke early studies by Dieck which revealed negligible structural changes to the ligand, regardless of the nature of the metal to which it was bonded. ${ }^{16}$ Of course, bond metric data are not the only indicators of the relative strength of $\pi$ back-donation; vibrational and UV-vis spectroscopy also offer a measure of the level of the interaction arising between metal and ligand. It is nevertheless striking that no significant structural changes are observed in the bipyridyl ligand in homologous series of complexes for which the degree of metal to ligand $\pi^{*}$ donation might reasonably be expected to vary significantly.

We recently reported a bona fide example of a transitionmetal complex of the bipyridyl radical anion, which was characterized in $[\mathrm{K}(2,2,2$-crypt $)]\left[\mathrm{Fe}\left(2,2^{\prime}\right.\right.$-bipy $\left.)(\text { mes })_{2}\right] .{ }^{17}$ To our knowledge, $3^{-}$is the first transition-metal complex for which single-crystal X-ray diffraction, Mössbauer, IR, Raman, and EPR spectroscopy, SQUID magnetometry, and density functional theory combine to give an unequivocal formulation as a complex of the $2,2^{\prime}$-bipyridyl radical anion. Herein we extend this work by reporting the synthesis of a homologous series of neutral $\left[\mathrm{M}\left(2,2^{\prime}\right.\right.$-bipy $\left.)(\mathrm{mes})_{2}\right](\mathrm{M}=\mathrm{Cr}(\mathbf{1}), \mathrm{Mn}$ (2), $\mathrm{Co}(4), \mathrm{Ni}(5))$ complexes and their chemical reduction to yield the closely related anionic species $\left[\mathrm{M}\left(2,2^{\prime} \text {-bipy }\right)(\mathrm{mes})_{2}\right]^{-}$ $\left(1^{-}, 2^{-}, 4^{-}\right.$, and $\left.5^{-}\right)$. These species were characterized by single-crystal X-ray diffraction, IR and Raman spectroscopy, EPR spectroscopy, SQUID magnetometry, and calculations at the DFT level. The data converge to indicate that all of the anionic species contain the radical anionic ligand $2,2^{\prime}$-bipy ${ }^{\bullet-}$.

\section{EXPERIMENTAL SECTION}

General Methods. All reactions and product manipulations were carried out under an inert atmosphere employing standard Schlenkline or glovebox techniques. $\mathrm{Mg}$ turnings (Fisher) and 2bromomesitylene (99\%, Alfa Aesar) were used as received. Potassium metal (99.95\%, Aldrich), $\mathrm{CrCl}_{2}$ (99.9\%, Strem), $\mathrm{MnCl}_{2}$ (97\%, Strem), $\mathrm{CoBr}_{2}$ (Co 26.6\% min, Alfa Aesar), $\mathrm{NiBr}_{2}$ (99+\%, Strem), 2,2'bipyridine (>99\%, TCI Europe), $\mathrm{PMe}_{3}$ (99\%, Fluorochem), $\mathrm{PEt}_{2} \mathrm{Ph}$ (98\%, Alfa Aesar), 18-crown-6 (1,4,7,10,13,16-hexaoxacyclooctadecane; 99\%, Alfa Aesar), dibenzo-18-crown-6 (2,3,11,12-dibenzo1,4,7,10,13,16-hexaoxacyclooctadeca-2,11-diene; 98\% Aldrich), and 2,2,2-crypt $(4,7,13,16,21,24$-hexaoxa-1,10-diazabicyclo[8.8.8]hexacosane; $\geq 99 \%$ Merck) were stored under dinitrogen in an MBraun UNIlab glovebox $\left(<0.1 \mathrm{ppm} \mathrm{H}_{2} \mathrm{O}\right.$ and $\left.<0.1 \mathrm{ppm} \mathrm{O}_{2}\right)$ and used as received. $\left[\mathrm{Cr}\left(\mathrm{PMe}_{3}\right)_{2}(\mathrm{mes})_{2}\right], \mathrm{Mn}_{3}(\mathrm{mes})_{6}$ (mes $=2,4,6$ $\left.\mathrm{Me}_{3} \mathrm{C}_{6} \mathrm{H}_{2}\right),\left[\mathrm{Co}\left(\mathrm{PPhEt}_{2}\right)_{2}(\mathrm{mes})_{2}\right]$, and $\left[\mathrm{Ni}\left(2,2^{\prime}\right.\right.$-bipy $\left.)(\mathrm{mes})_{2}\right]$ (5) were synthesized according to previously reported literature methods. ${ }^{18-21}\left[\mathrm{Cr}\left(2,2^{\prime}\right.\right.$-bipy $\left.)(\mathrm{mes})_{2}\right]$ was synthesized according to a modified procedure using $\left[\mathrm{Cr}\left(\mathrm{PMe}_{3}\right)_{2}(\mathrm{mes})_{2}\right]$ as a precursor. ${ }^{22}$ Toluene (tol; 99.9\%, Rathburn Chemicals, Ltd.), pentane (99.9\% Rathburn Chemicals, Ltd.), and diethylether (99.9\%, Fisher, stabilized with copper gauze) were dried using an MBraun SPS-800 solvent purification system. Tetrahydrofuran (THF; 99\%, Rathburn Chemicals, Ltd.) and pyridine (py; 99+\%, Alfa Aesar) were distilled over sodium/benzophenone and $\mathrm{CaH}_{2}$, respectively. All solvents were stored in gastight ampules under argon. In addition, toluene, THF, diethyl ether, and hexanes were stored over activated $3 \AA$ molecular sieves (Acros).

$\left[\mathrm{Cr}\left(2,2^{\prime}\right.\right.$-bipy) $\left.(\mathrm{mes})_{2}\right] \cdot 1.5 \mathrm{C}_{6} \mathrm{H}_{6} \quad\left(\mathbf{1} \cdot 1.5 \mathrm{C}_{6} \mathrm{H}_{6}\right) .\left[\mathrm{Cr}\left(\mathrm{PMe}_{3}\right)_{2}(\mathrm{mes})_{2}\right]$ $(100 \mathrm{mg}, 0.226 \mathrm{mmol})$ and $2,2^{\prime}$-bipyridine $(52.9 \mathrm{mg}, 0.339 \mathrm{mmol})$ were stirred in THF $(5 \mathrm{~mL})$ for $30 \mathrm{~min}$, giving rise to a dark purple solution. Following filtration, the solution was layered with hexanes, yielding small, purple platelike crystals of $\left[\mathrm{Cr}\left(2,2^{\prime}\right.\right.$-bipy $\left.)(\mathrm{mes})_{2}\right] \cdot \mathrm{THF}$ after 4 days. ${ }^{22 \mathrm{C}}$ Similar diffusion into a benzene solution yielded higher quality crystals of $\left[\mathrm{Cr}\left(2,2^{\prime}\right.\right.$-bipy $\left.)(\mathrm{mes})_{2}\right] \cdot 1.5 \mathrm{C}_{6} \mathrm{H}_{5}\left(\mathbf{1} \cdot 1.5 \mathrm{C}_{6} \mathrm{H}_{5}\right)$ in greater crystalline yields $(60 \%$ yield). The solvent of crystallization was found to be removed when samples were sealed under vacuum; as a result, we were unable to obtain a powder X-ray diffractogram due to a loss of crystallinity. Anal. Calcd for $\mathrm{C}_{28} \mathrm{H}_{30} \mathrm{~N}_{2} \mathrm{Cr}$ : C, 75.31; H, 6.77; N, 6.27. Found: C, 74.95; H, 6.60; N, 6.06. IR $\left(\mathrm{cm}^{-1}\right): 650(\mathrm{w}), 733(\mathrm{~m})$, $756(\mathrm{~s}), 767(\mathrm{~m}), 800(\mathrm{w}), 842(\mathrm{~m}), 1015(\mathrm{~m}), 1059(\mathrm{w}), 1153(\mathrm{~m})$, $1171(\mathrm{w}), 1244(\mathrm{w}), 1260(\mathrm{w}), 1311(\mathrm{w}), 1377(\mathrm{~s}), 1429(\mathrm{w}), 1441$ (s), $1458(\mathrm{~s}), 1562(\mathrm{w}), 1571(\mathrm{w}), 1600(\mathrm{~s}) . \operatorname{Raman}\left(\mathrm{cm}^{-1}\right)$ : $132(\mathrm{w})$, $371(\mathrm{w}), 650(\mathrm{w}), 1016(\mathrm{~s}), 1159(\mathrm{~m}), 1170(\mathrm{~m}), 1227(\mathrm{~m}), 1282(\mathrm{~s})$, $1318(\mathrm{~m}), 1414(\mathrm{w}), 1468(\mathrm{~m}), 1487$ (s), $1510(\mathrm{w}), 1554(\mathrm{~m}), 1561$ (w), $1572(\mathrm{w})$. A solid-state EPR spectrum was recorded at room temperature and exhibited a very weak resonance with a $g$ factor of 1.986.

[Mn(2,2'-bipy)(mes) $]$ (2). $\mathrm{Mn}_{3}(\mathrm{mes})_{6}(150.0 \mathrm{mg}, 0.171 \mathrm{mmol})$ and $2,2^{\prime}$-bipy $(80.0 \mathrm{mg}, 0.512 \mathrm{mmol})$ were weighed out into a sample vial and dissolved in THF $(5 \mathrm{~mL})$ inside an inert atmosphere glovebox, and the solution was stirred for $6 \mathrm{~h}$. The resultant dark blue solution was filtered and layered with hexanes. After 3 days, very small, flat, needlelike crystals of $\left[\mathrm{Mn}\left(2,2^{\prime}\right.\right.$-bipy $\left.)(\mathrm{mes})_{2}\right]$ (2) had formed, which were found to be suitable for single-crystal X-ray diffraction $(121 \mathrm{mg}, 52 \%$ crystalline yield). A powder X-ray diffraction pattern was collected on the bulk sample and found to match that calculated from the single-crystal X-ray diffraction data. Anal. Calcd for $\mathrm{C}_{28} \mathrm{H}_{30} \mathrm{~N}_{2} \mathrm{Mn}$ : C, 74.82; H, 6.73; N, 6.23. Found: C, 74.62; H, 6.70; N, 6.15. IR $\left(\mathrm{cm}^{-1}\right): 627(\mathrm{w}), 645(\mathrm{w}), 665(\mathrm{w}), 704(\mathrm{w}), 707(\mathrm{w}), 737$ (m), $743(\mathrm{w}), 763(\mathrm{~m}), 799(\mathrm{w}), 839(\mathrm{~m}), 850(\mathrm{~m}), 892(\mathrm{w}), 934(\mathrm{w})$, $963(\mathrm{w}), 1012(\mathrm{~s}), 1043(\mathrm{w}), 1058(\mathrm{w}), 1102(\mathrm{w}), 1112(\mathrm{w}), 1157(\mathrm{~s})$, $1167(\mathrm{w}), 1210(\mathrm{~m}), 1246(\mathrm{~m}), 1257(\mathrm{w}), 1279(\mathrm{w}), 1314(\mathrm{~m}), 1365$ (w), $1374(\mathrm{~m}), 1390(\mathrm{w}), 1485(\mathrm{w}), 1528(\mathrm{w}), 1562(\mathrm{w}), 1571(\mathrm{w})$, $1588(\mathrm{~m}), 1596(\mathrm{~s}), 1600(\mathrm{~s}), 1701(\mathrm{w}), 1726(\mathrm{w})$. Raman $\left(\mathrm{cm}^{-1}\right): 95$ $(\mathrm{w}), 130(\mathrm{~s}), 235(\mathrm{~m}), 289(2), 351(\mathrm{w}), 413(\mathrm{w}), 482(\mathrm{w}), 541(\mathrm{w})$, $627(w), 647(w), 766(w), 883(w), 919(w), 937(w), 1013(s), 1140$ $(w), 1168(w), 1245(w), 1280(w), 1302(w), 1311(w), 1487(s)$, $1563(\mathrm{w}), 1597(\mathrm{w}), 1613(\mathrm{w}), 1721(\mathrm{w})$. A solid-state EPR spectrum 
of a sample of 2 diluted with $\left[\mathrm{NBu}_{4}\right]\left[\mathrm{PF}_{6}\right]$ was recorded at room temperature and exhibited an extremely broad resonance centered at a $g$ factor of 2.009 .

[Co(2,2'-bipy)(mes) $\left.)_{2}\right] \cdot$ THF (4-THF). $\left[\mathrm{Co}\left(\mathrm{PEt}_{2} \mathrm{Ph}\right)_{2}(\mathrm{mes})_{2}\right](301.1$ $\mathrm{mg}, 0.478 \mathrm{mmol})$ and $2,2^{\prime}$-bipy $(74.9 \mathrm{mg}, 0.480 \mathrm{mmol})$ were weighed out into a Schlenk tube in a glovebox. The reaction vessel was transferred to a Schlenk line. The solids were dissolved in THF $(\sim 5$ $\mathrm{mL}$ ), and the solution was stirred for $16 \mathrm{~h}$. During this time the brown-yellow solution turned dark red. The reaction mixture was filtered and layered with hexanes. After 3 days, dark blocklike crystals of $\left[\mathrm{Co}\left(2,2^{\prime}\right.\right.$-bipy $\left.)(\text { mes })_{2}\right]$.THF (4.THF) had formed and were found to be suitable for single-crystal X-ray diffraction (101.1 mg, $40 \%$ crystalline yield). Variable-temperature single-crystal X-ray diffraction experiments showed significant variations in the lattice parameters of $\left[\mathrm{Co}\left(2,2^{\prime}\right.\right.$-bipy $\left.)(\mathrm{mes})_{2}\right] \cdot$ THF as a function of temperature (see the Supporting Information for full details). A room-temperature powder $\mathrm{X}$-ray diffraction pattern was collected on the bulk sample and found to match that calculated from single-crystal X-ray diffraction data collected at $293 \mathrm{~K}$. The elemental analyses recorded for this compound indicate that the samples lose solvent of crystallization under vacuum (the same effect was observed for $\mathbf{1} \cdot \mathrm{C}_{6} \mathrm{H}_{6}$ ). Anal. Calcd for $\mathrm{C}_{28} \mathrm{H}_{30} \mathrm{~N}_{2} \mathrm{Co}$ : C, 73.12; H, 7.29; N, 5.33. Found: C, 72.68; H, 7.09; $\mathrm{N}$, 5.55. IR $\left(\mathrm{cm}^{-1}\right): 408(\mathrm{~m}), 415(\mathrm{~m}), 440(\mathrm{w}), 465$ (vs, broad), 648 $(\mathrm{w}), 652(\mathrm{w}), 668(\mathrm{w}), 712(\mathrm{w}), 721(\mathrm{~m}), 728(\mathrm{~m}), 736(\mathrm{w}), 754(\mathrm{~s})$, $874(\mathrm{w}), 889(\mathrm{w}), 917(\mathrm{w}), 935(\mathrm{~m}), 962(\mathrm{w}), 984(\mathrm{w}), 1008(\mathrm{~m})$, $1018(\mathrm{w}), 1030(\mathrm{w}), 1042(\mathrm{w}), 1061(\mathrm{~m}), 1069(\mathrm{w}), 1116(\mathrm{w}), 1152$ (m), $1161(\mathrm{~m}), 1215(\mathrm{w}), 1245(\mathrm{w}), 1262(\mathrm{w}), 1272(\mathrm{~m}), 1291(\mathrm{w})$, $1308(\mathrm{w}), 1309(\mathrm{~m}), 1553(\mathrm{w}), 1564(\mathrm{w}), 1592(\mathrm{w}), 1600(\mathrm{w})$. Raman $\left(\mathrm{cm}^{-1}\right)$ : $104(\mathrm{w}), 126(\mathrm{w}), 229(\mathrm{w}), 365(\mathrm{~m}), 419(\mathrm{w}), 544(\mathrm{w}), 558$ (w), $650(\mathrm{~m}), 733(\mathrm{w}), 934(\mathrm{w}), 1004(\mathrm{~m}), 1029(\mathrm{w}), 1101(\mathrm{w}), 1163$ (m), 1259 (m), 1268 (m), 1317 (m), 1477 (s), 1554 (s), 1600 (s). A solid-state EPR spectrum was recorded at room temperature and exhibited an extremely broad resonance with a $g$ factor of 2.428 .

$\left[\mathrm{Ni}\left(2,2^{\prime}\right.\right.$-bipy $\left.)(\mathrm{mes})_{2}\right](5)$. This sample was prepared following a previously published method. ${ }^{21}$ A THF solution of 5 was layered with pentane, yielding dark purple crystals of the title compound. The bulk sample was characterized by powder X-ray diffraction and found to match the calculated diffractogram for the single crystal structure. Anal. Calcd for $\mathrm{C}_{28} \mathrm{H}_{30} \mathrm{~N}_{2} \mathrm{Ni}$ : C, 74.20; H, 6.67; N, 6.18. Found: C, 74.42; H, 6.56; N, 6.05. IR $\left(\mathrm{cm}^{-1}\right): 713(\mathrm{w}), 722(\mathrm{~m}), 729(\mathrm{~m}), 737(\mathrm{w}), 756$ (s), $843(\mathrm{~m}), 874(\mathrm{w}), 889(\mathrm{w}), 940(\mathrm{w}), 1015(\mathrm{~m}), 1021(\mathrm{~m}), 1063$ $(\mathrm{w}), 1153(\mathrm{w}), 1168(\mathrm{w}), 1218(\mathrm{w}), 1242(\mathrm{w}), 1250(\mathrm{w}), 1256(\mathrm{w})$, $1278(\mathrm{w}), 1313(\mathrm{w}), 1340(\mathrm{w}), 1362(\mathrm{~m}), 1377(\mathrm{~m}), 1394(\mathrm{w}), 1405$ $(\mathrm{w}), 1419(\mathrm{w}), 1430(\mathrm{~m}), 1443(\mathrm{~s}), 1562(\mathrm{w}), 1569(\mathrm{w}), 1604(\mathrm{w})$. Raman $\left(\mathrm{cm}^{-1}\right)$ : $258(\mathrm{w}), 550(\mathrm{w}) 566(\mathrm{~m}), 635(\mathrm{w}), 772(\mathrm{w}), 943$ (w), $1016(\mathrm{~s}), 1170(\mathrm{~s}), 1279$ (s), 1325 (s), 1488 (s), 1564 (s), 1606 (m). ${ }^{1} \mathrm{H}$ NMR ( $d_{6}$-benzene): $\delta(\mathrm{ppm}) 8.05\left(\mathrm{~d}, 2 \mathrm{H},{ }^{3} \mathrm{~J}=6 \mathrm{~Hz}\right.$, bipyH $\left._{3,3^{\prime}}\right), 6.92$ (s, $\left.4 \mathrm{H}, \mathrm{HMes}\right), 6.75$ (dd, $2 \mathrm{H},{ }^{3} \mathrm{~J}=6 \mathrm{~Hz}$, bipyH $\left._{5,5^{\prime}}\right)$, $6.65\left(\mathrm{~d}, 2 \mathrm{H}\right.$, bipyH $\left._{6,6^{\prime}}\right), 6.14\left(\mathrm{dd}, 2 \mathrm{H}\right.$, bipyH $\left._{4,4^{\prime}}\right), 3.04\left(\mathrm{~s}, 12 \mathrm{H}, o-\mathrm{CH}_{3}\right)$, $2.41\left(\mathrm{~s}, 6 \mathrm{H}, p-\mathrm{CH}_{3}\right) \cdot{ }^{13} \mathrm{C}$ NMR ( $d_{6}$-benzene): $\delta(\mathrm{ppm}) 157.0,153.9$, $150.3,144.3,135.6,131.7,126.8,126.7,120.0,27.9,21.5$.

[K(dibenzo-18-crown-6) $\mathrm{THF}]\left[\mathrm{Cr}\left(2,2^{\prime}\right.\right.$-bipy)(mes) $\left.{ }_{2}\right] \cdot 2 \mathrm{THF} \quad$ ([K(dibenzo-18-crown-6) -THF][1-].2THF). A mixture of $1(75.0 \mathrm{mg}$, $0.15 \mathrm{mmol}), \mathrm{KC}_{8}(22.7 \mathrm{mg}, 0.17 \mathrm{mmol})$, and dibenzo-18-crown-6 $(60.5 \mathrm{mg}, 0.17 \mathrm{mmol})$ were weighed out into a sample vial in a glovebox and dissolved in approximately $5 \mathrm{~mL}$ of THF. The reaction mixture was stirred for $4 \mathrm{~h}$. Subsequent filtration and layering with hexanes yielded dark brown crystals of [K(dibenzo-18-crown$6) \cdot \mathrm{THF}]\left[1^{-}\right] \cdot 2 \mathrm{THF}$ suitable for single-crystal X-ray diffraction $(40$ $\mathrm{mg}, 26 \%$ crystalline yield). Solid samples were found to lose crystallinity upon grinding, and subsequently a satisfactory PXRD diffractogram could not be collected. Due to the high air and moisture sensitivity of the sample suitable elemental analyses could not be obtained. IR $\left(\mathrm{cm}^{-1}\right)$ : $726(\mathrm{~s}), 744(\mathrm{w}), 841(\mathrm{w}), 943(\mathrm{~s}), 958(\mathrm{~m})$, $1061(\mathrm{~m}), 1087(\mathrm{w}), 1126(\mathrm{~s}), 1209(\mathrm{~m}), 1251(\mathrm{~s}), 1290(\mathrm{~m}), 1377$ (s), $1419(\mathrm{w}), 1489(\mathrm{~m}), 1503(\mathrm{~m}), 1593(\mathrm{w})$. Raman $\left(\mathrm{cm}^{-1}\right): 209$ (m), $269(\mathrm{w}), 360(\mathrm{~s}), 411(\mathrm{w}), 462(\mathrm{w}), 578(\mathrm{w}), 603(\mathrm{~m}), 643(\mathrm{~s})$, $748(\mathrm{w}), 945(\mathrm{w}), 995(\mathrm{~s}), 1011(\mathrm{w}), 1080(\mathrm{~m}), 1161(\mathrm{~s}), 1203(\mathrm{~s})$, $1273(\mathrm{~m}), 1288(\mathrm{w}), 1354(\mathrm{w}), 1416(\mathrm{~m}), 1480(\mathrm{~s}), 1507(\mathrm{~s}), 1536$ (m), $1568(\mathrm{~m})$. Solid-state EPR spectra were recorded at room temperature and at $10 \mathrm{~K}$, revealing a broadened resonance alongside a much stronger sharp resonance with a $g$ factor of 1.986 .

[K(18-crown-6)][Mn(2,2'-bipy)(mes) $\left.{ }_{2}\right] \cdot x($ solv) ([K(18-crown6)][2] $[x($ solv $))$. THF $(5 \mathrm{~mL})$ was added to a sample vial containing $2(66.0 \mathrm{mg}, 0.147 \mathrm{mmol}), \mathrm{K}$ metal $(6.1 \mathrm{mg}, 0.16 \mathrm{mmol})$, and 18 crown-6 $(39.0 \mathrm{mg}, 0.148 \mathrm{mmol})$ in a glovebox, and the mixture was stirred for $24 \mathrm{~h}$. Filtration yielded a dark brown solution which when layered with hexanes produced crystals of $[\mathrm{K}(18$-crown-6)][Mn(2,2'-

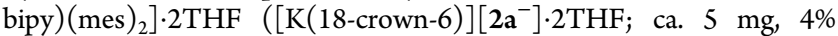
crystalline yield). Due to the small size and weakly diffracting nature of the crystalline samples, single-crystal X-ray diffraction data were collected at Beam Station I19 at the Diamond Light Source Synchrotron. Better quality crystalline samples suitable for singlecrystal X-ray diffraction on in-house instrumentation could be obtained from pyridine solutions which were allowed to diffuse into a toluene layer. These crystals were characterized as $[\mathrm{K}(18$-crown$6)]\left[\mathrm{Mn}\left(2,2^{\prime}\right.\right.$-bipy $\left.)(\mathrm{mes})_{2}\right] \cdot 0.67 \mathrm{py} \cdot 0.67 \mathrm{tol} \quad([\mathrm{K}(18$-crown-6) $]$ $\left.\left[2 \mathbf{b}^{-}\right] \cdot 0.67 \mathrm{py} \cdot 0.67 \mathrm{tol}\right)$. Due to the low yields of this reaction and the poor stability of the complex, suitable PXRD data and an elemental analysis of the bulk product were unattainable. IR $\left(\mathrm{cm}^{-1}\right): 600(\mathrm{w})$, $619(\mathrm{w}), 639(\mathrm{w}), 665(\mathrm{w}), 680(\mathrm{w}), 725(\mathrm{~m}), 755(\mathrm{w}), 797(\mathrm{w}), 832$ (w), $843(\mathrm{w}), 930(\mathrm{w}), 945(\mathrm{w}), 951(\mathrm{~s}), 990(\mathrm{w}), 1011(\mathrm{~m}), 1055$ $(\mathrm{w}), 1077(\mathrm{w}), 1101(\mathrm{~s}), 1130(\mathrm{~m}), 1144(\mathrm{~m}), 1172(\mathrm{w}), 1209(\mathrm{w})$, 1235 (w), 1260 (s), 1273 (w), 1289 (s), $1294(\mathrm{w}), 1352(\mathrm{~s}), 1358(\mathrm{w})$, $1410(\mathrm{w}), 1419(\mathrm{~m}), 1493(\mathrm{~m}), 1506(\mathrm{w}), 1540(\mathrm{w}), 1558(\mathrm{w}), 1583$ (w), $1617(\mathrm{w}), 1655(\mathrm{w}), 1695(\mathrm{w}), 1744(\mathrm{w}), 1807(\mathrm{w}), 1866(\mathrm{w})$. Raman $\left(\mathrm{cm}^{-1}\right)$ : $127(\mathrm{w}), 237(\mathrm{w}), 287(\mathrm{w}), 343(\mathrm{w}), 524(\mathrm{w}), 632$ (w), $738(\mathrm{w}), 963(\mathrm{w}), 984(\mathrm{~m}), 1070(\mathrm{w}), 1159(\mathrm{~m}), 1201(\mathrm{~m}), 1268$ (w), 1348 (w), $1458(\mathrm{w}), 1478$ (s), $1500(\mathrm{~m}), 1534$ (w), 1559 (w), $1579(\mathrm{w})$. Solid- and solution-phase EPR spectra were recorded at room temperature, revealing a strong resonance centered at a $g$ factor of 2.003. This very strong resonance arising from the bipyridyl radical was observed over a much broader resonance, similar to that observed for 2.

[K(2,2,2-crypt)][Co(2,2'-bipy)(mes) $\left.{ }_{2}\right]$ ([K(2,2,2-crypt)][4- $\left.]\right)$. A mixture of $4(50.0 \mathrm{mg}, 0.110 \mathrm{mmol}), \mathrm{K}$ metal $(5.2 \mathrm{mg}, 0.13 \mathrm{mmol})$, and 2,2,2-crypt $(41.5 \mathrm{mg}, 0.110 \mathrm{mmol})$ were dissolved in approximately $5 \mathrm{~mL}$ of THF, and the mixture was stirred for $16 \mathrm{~h}$ in a glovebox to yield a dark brown solution. Filtration and layering with hexanes yielded crystals of $[\mathrm{K}(2,2,2$-crypt $)]\left[\mathrm{Co}\left(2,2^{\prime}\right.\right.$-bipy $)$ $\left.(\mathrm{mes})_{2}\right]$ after 10 days $(25.4 \mathrm{mg}, 26 \%$ crystalline yield). A powder Xray diffraction pattern was found to match that calculated from the single-crystal structure. Anal. Calcd for $\mathrm{C}_{46} \mathrm{CoH}_{66} \mathrm{KN}_{4} \mathrm{O}_{6}: \mathrm{C}, 63.57 ; \mathrm{H}$, 7.65; N, 6.45. Found: C, 63.26; H, 7.49; N, 6.45. IR $\left(\mathrm{cm}^{-1}\right)$ : $608(\mathrm{w})$, $638(\mathrm{w}), 667(\mathrm{w}), 682(\mathrm{w}), 714(\mathrm{w}), 729(\mathrm{~s}), 756(\mathrm{w}), 782(\mathrm{w}), 832$ $(\mathrm{w}), 841(\mathrm{~m}), 864(\mathrm{w}), 934(\mathrm{~s}), 943(\mathrm{w}), 956(\mathrm{~s}), 1003(\mathrm{w}), 1019(\mathrm{w})$, $1027(\mathrm{w}), 1076(\mathrm{~m}), 1088(\mathrm{w}), 1107(\mathrm{~s}), 1130(\mathrm{~m}), 1162(\mathrm{w}), 1173$ $(\mathrm{w}), 1211(\mathrm{w}), 1231(\mathrm{w}), 1258(\mathrm{~m}), 1276(\mathrm{w}), 1289(\mathrm{~s}), 1295(\mathrm{~m})$, $1341(\mathrm{w}), 1351$ (s), $1359(\mathrm{~m}), 1419(\mathrm{w}), 1496(\mathrm{~s}), 1556(\mathrm{~m}), 1564$ $(\mathrm{m}), 1661(\mathrm{w}), 1699(\mathrm{w}), 1726(\mathrm{w}), 1754(\mathrm{w}), 1783(\mathrm{w})$. Raman $\left(\mathrm{cm}^{-1}\right)$ : $72(\mathrm{~m}), 80(\mathrm{~m}), 88(\mathrm{~m}), 96(\mathrm{~m}), 103(\mathrm{~m}), 112(\mathrm{~m}), 120(\mathrm{~m})$, $126(\mathrm{w}), 136(\mathrm{~m}), 225(\mathrm{w}), 365(\mathrm{~m}), 635(\mathrm{w}), 803(\mathrm{~m}$, broad), 998 $(\mathrm{m}), 1143(\mathrm{~m}), 1207(\mathrm{w}), 1271(\mathrm{w}), 1445(\mathrm{~s}), 1506(\mathrm{~m}), 1552(\mathrm{~m})$, 1809 (w), 2328 (s), 2440 (w, broad), 2587 (w, broad), 2885 (w, broad). A solid-state EPR spectrum was recorded at room temperature and exhibited a broad resonance at $g=2.189$ with a small, sharper resonance at ca. $g=2.016$

[K(2,2,2-crypt)][Ni(2,2'-bipy)(mes) $\left.{ }_{2}\right] \quad$ ([K(2,2,2-crypt)][5']). THF $(5 \mathrm{~mL})$ was added to a sample vial containing $5(50.0 \mathrm{mg}$, $0.110 \mathrm{mmol}), \mathrm{KC}_{8}(14.9 \mathrm{mg}, 0.11 \mathrm{mmol})$, and 2,2,2-crypt (41.5 mg, $0.110 \mathrm{mmol}$ ), and the mixture was stirred in a glovebox for $4 \mathrm{~h}$. Filtration and layering with hexanes yielded dark purple crystals of $[\mathrm{K}(2,2,2$-crypt $)]\left[\mathrm{Ni}\left(2,2^{\prime}\right.\right.$-bipy $\left.)(\text { mes })_{2}\right]$, suitable for single-crystal X-ray diffraction (13\% crystalline yield). A powder X-ray diffraction pattern matched that calculated from the single-crystal structure. Due to the high air and moisture sensitivity of this sample, an entirely satisfactory elemental analysis could not be obtained. Anal. Calcd for $\mathrm{C}_{46} \mathrm{H}_{66} \mathrm{~N}_{4} \mathrm{NiKO}_{6}: \mathrm{C}, 63.57 ; \mathrm{H}, 7.66 ; \mathrm{N}, 6.45$. Found: $\mathrm{C}, 61.02 ; \mathrm{H}$, 7.29; N, 6.50. IR ( $\left.\mathrm{cm}^{-1}\right)$ : $674(\mathrm{w}), 717(\mathrm{~m}), 756(\mathrm{w}), 805(\mathrm{w}), 822$ (w), $841(\mathrm{w}), 935(\mathrm{~m}), 959(\mathrm{~m}), 1010(\mathrm{~m}), 1018(\mathrm{w}), 1077(\mathrm{~m}), 1107$ 
(s), $1129(\mathrm{~m}), 1159(\mathrm{w}), 1203(\mathrm{w}), 1261(\mathrm{~m}), 1275(\mathrm{~m}), 1285(\mathrm{w})$, $1294(\mathrm{w}), 1351(\mathrm{~m}), 1360(\mathrm{~m}), 1378(\mathrm{~s}), 1416(\mathrm{w}), 1488(\mathrm{~m}), 1569$ $(\mathrm{w})$. Raman $\left(\mathrm{cm}^{-1}\right)$ : $155(\mathrm{w}), 366(\mathrm{w}), 413(\mathrm{w}), 544(\mathrm{w}), 561(\mathrm{w})$, $647(\mathrm{w}), 746(\mathrm{~m}), 940(\mathrm{w}), 999(\mathrm{~s}), 1016(\mathrm{~m}), 1086(\mathrm{w}), 1156(\mathrm{~s})$, $1201(\mathrm{~s}), 1272(\mathrm{~m}), 1314(\mathrm{w}), 1353(\mathrm{~m}), 1413(\mathrm{~m}), 1493(\mathrm{~s}), 1549$ $(\mathrm{s}), 1597(\mathrm{w})$. Solid-state EPR spectra were recorded at room temperature and at $10 \mathrm{~K}$, revealing a strong resonance with a $g$ factor of 2.010. A solution-phase spectrum was also collected, exhibiting hyperfine coupling indicative of a ligand radical, as previously reported in ref 21.

X-ray Diffraction. Single-crystal X-ray diffraction data were collected using an Enraf-Nonius Kappa-CCD diffractometer or using synchrotron radiation on a CrystalLogic Kappa (three-circle) diffractometer at beamline I19 (EH1) at the Diamond Light Source, Didcot, Oxfordshire, U.K. Crystals were selected under Paratone-N oil, mounted on MiTeGen loops, and quench-cooled using an open flow $\mathrm{N}_{2}$ cooling device. ${ }^{23}$ The laboratory data were collected at $150 \mathrm{~K}$ using graphite-monochromated Mo $\mathrm{K} \alpha$ radiation and processed using the DENZO-SMN package, including unit cell parameter refinement and interframe scaling (which was carried out using SCALEPACK within DENZO-SMN). ${ }^{24}$ The synchrotron data were collected at the zirconium edge $(\lambda=0.6889 \AA)$ and were processed using CrystalClear-SM Expert $2.0 \mathrm{r} 4 .^{25}$ Structures were subsequently solved using direct methods and refined on $F^{2}$ using the SHELXL 97-2 package. $^{26}$

Transmission powder X-ray patterns were recorded using a Siemens D5000 diffractometer in modified Debye-Scherrer geometry equipped with an MBraun position-sensitive detector. The instrument produced $\mathrm{Cu} \mathrm{K} \alpha_{1}$ radiation $(\lambda=1.54056 \AA)$ using a germanium monochromator and a standard $\mathrm{Cu}$ source. Data were recorded on samples in flame-sealed capillaries under dinitrogen. The capillaries were mounted on a goniometer head and aligned so that rotation occurred along the long central axis of the capillary. During a measurement the capillary was rotated at $\sim 60 \mathrm{rpm}$ in order to minimize any preferred orientation effects that might occur.

SQUID Magnetometry. Magnetic properties were measured on unanchored polycrystalline samples with a Quantum Design MPMS XL SQUID magnetometer. Due to the extreme air and moisture sensitivity of the complexes, they were flame-sealed under vacuum in Suprasil tubes. Samples 1 and $\mathbf{2}$ were cooled to $2 \mathrm{~K}$ in zero applied field and their magnetic susceptibilities measured between 2 and $300 \mathrm{~K}$ in a $0.01 \mathrm{~T}$ field. The samples were subsequently field-cooled to $2 \mathrm{~K}$ and magnetic susceptibility measurements collected upon warming at regular intervals in a $0.01 \mathrm{~T}$ field. The resulting zero-field-cooled and field-cooled results were virtually identical and have been merged. Magnetic measurements on $\mathbf{4}$ were conducted in a similar fashion but in a $0.02 \mathrm{~T}$ magnetic field. Diamagnetic corrections were applied to the measured molar magnetic susceptibilities of all of the complexes. ${ }^{27}$ The absence of ferromagnetic impurities in samples of $\mathbf{1}$ and $\mathbf{2}$ was confirmed by variable field measurements of molar magnetization at $300 \mathrm{~K}$ : nonlinearity of the magnetization vs field plot is indicative of such impurities (see Figure S27 in the Supporting Information). Similar room-temperature isothermal magnetization measurements were also performed for the four novel compounds containing a 2,2'bipyridyl radical, $\mathbf{1}^{-}, \mathbf{2}^{-}, \mathbf{4}^{-}$, and $\mathbf{5}^{-}$(see Figure S28 in the Supporting Information). A linear plot of magnetization vs field in the case of $\mathbf{1}^{-}$ indicated that there were no ferromagnetic impurities, and the magnetic measurements were performed as described for $\mathbf{1}$. For the remainder of the compounds, by contrast, the $S$-shaped dependence of the magnetization vs field curve is a clear indication of the presence of ferromagnetic impurities. In these cases, we distinguish the intrinsic susceptibility of $2^{-}, 4^{-}$, and $5^{-}$from that of trace ferromagnetic impurities by measuring the magnetization at five applied fields between 4 and $5 \mathrm{~T}$ following an initial zero-field cooling to $2 \mathrm{~K}$. The samples were warmed to $300 \mathrm{~K}$ in small increments and the magnetization measured at each step at the same five fields. The slope of the resulting linear plot of the molar magnetization as a function of applied field was used to obtain the molar magnetic susceptibility at each temperature. The procedure is illustrated in Figure S29 of the Supporting Information. Diamagnetic corrections were applied to the measured molar magnetic susceptibilities. ${ }^{27}$ In some cases we were unable to measure magnetic data below $20 \mathrm{~K}$ due to technical issues. In order to ensure a balanced treatment of all systems, only data above $20 \mathrm{~K}$ were used in the fitting of the magnetic data, even where lower temperature data were available.

Computational Methods. All calculations described in this paper were performed using density functional theory as implemented in the ORCA program. ${ }^{28}$ Unrestricted geometry optimizations on all $\left[\mathrm{M}\left(2,2^{\prime} \text {-bipy }\right)(\mathrm{mes})_{2}\right]^{x-}(x=0,1)$ species were carried out using the B3LYP functional, ${ }^{29}$ in combination with the TZVP basis set of Ahlrichs and co-workers on $\mathrm{M}$ and all coordinating atoms $(\mathrm{N}(1)$, $\mathrm{N}(2), \mathrm{C}(11), \mathrm{C}(21))^{30}$ and the SVP basis set elsewhere. ${ }^{31}$ Initial atomic coordinates were taken from single-crystal X-ray diffraction experiments. Stationary points were confirmed to be minima by the absence of imaginary frequencies.

Additional Characterization Techniques. IR data were recorded on solid samples in Nujol mulls. The mulls were made up inside an inert-atmosphere glovebox and the $\mathrm{KBr}$ plates placed in an airtight container prior to data collection. Spectra were recorded on a Nicolet Magna-IR 560 spectrometer in absorbance mode (HappGenzel FT apodization) with a Ge/CsI beam splitter and liquid nitrogen cooled mercury cadmium telluride (MCT) detector.

Raman spectra were recorded on solid samples under dinitrogen in flame-sealed Pyrex capillaries using a Dilor Labram 300 spectrometer. The excitation radiation was produced by a $20 \mathrm{~mW}$ helium-neon laser operating at a wavelength of $632.817 \mathrm{~nm}$. Optical density filters could be inserted into the beam to reduce photon flux, decreasing the likelihood that photochemical reactions would take place during the measurement. Typically, measurements were obtained at $0.1 \%$ of full intensity with a counting time of $100 \mathrm{~s}$. Calibration of the spectrometer was performed before each measurement by referencing to the $520.7 \mathrm{~nm}$ line of a silicon wafer.

CW EPR experiments were performed using an X-band Bruker BioSpin GmbH EMX spectrometer equipped with a high-sensitivity Bruker probe head and a low-temperature Oxford Instruments CF935 helium-flow cryostat. Experiments were conducted with $2-10 \mathrm{~mW}$ microwave power, $0.1 \mathrm{mT}$ modulation amplitude, and a modulation frequency of $100 \mathrm{kHz}$. The magnetic field was calibrated at room temperature with an external 2,2-diphenyl-1-picrylhydrazyl standard ( $g$ $=2.0036)$. Solid-state spectra were recorded on approximately $20 \mathrm{mg}$ of sample in airtight EPR tubes under argon.

$\mathrm{CHN}$ elemental analyses were performed on $5 \mathrm{mg}$ samples submitted under vacuum in flame-sealed Pyrex ampules.

\section{RESULTS AND DISCUSSION}

The neutral complexes $\left[\mathrm{M}\left(2,2^{\prime}\right.\right.$-bipy $\left.)(\mathrm{mes})_{2}\right](\mathrm{M}=\mathrm{Cr}(\mathbf{1}), \mathrm{Mn}$ (2), Co (4)) were synthesized by direct reaction of $\left[\mathrm{Cr}\left(\mathrm{PMe}_{3}\right)_{2}(\mathrm{mes})_{2}\right], \mathrm{Mn}_{3}(\mathrm{mes})_{6}$, or $\left[\mathrm{Co}\left(\mathrm{PEt}_{2} \mathrm{Ph}\right)_{2}(\mathrm{mes})_{2}\right]$ with $2,2^{\prime}$-bipyridine. $\left[\mathrm{Ni}\left(2,2^{\prime}\right.\right.$-bipy $\left.)(\mathrm{mes})_{2}\right]$ (5) was synthesized following the stepwise procedure previously reported by Klein. ${ }^{21}$ All four complexes were isolated as crystalline samples in $1 \cdot 1.5 \mathrm{C}_{6} \mathrm{H}_{6}, 2,4 \cdot \mathrm{THF}$, and 5 . The structures of 1,2 , and 4 as determined by single-crystal $\mathrm{X}$-ray diffraction are pictured in Figure 2. Crystallographic data and experimental parameters for the structures are presented in Table 1 . To the best of our knowledge, $\mathbf{2}$ and $\mathbf{4}$ have not been structurally characterized to date, while the structure we obtained for $\mathbf{1}$ is a different solvate of a complex first characterized by single-crystal X-ray diffraction by Gambarotta, Chiang, and co-workers. ${ }^{22 c}$ The neutral iron analogue 3 was previously reported by our research groups. $^{17}$

The torsion angle between the planes defined by $\mathrm{M} 1-\mathrm{C} 11-$ $\mathrm{C} 21$ and $\mathrm{M} 1-\mathrm{N} 1-\mathrm{N} 2$ indicates that the coordination geometries about the metal centers vary from almost square planar $\left(1,4\right.$, and $5, \phi=8.1,22.0$. and $12.4^{\circ}$, respectively) to pseudotetrahedral ( 2 and $3,70.6$ and $70.2^{\circ}$, respectively). The preference for a pseudo-square-planar geometry for $\mathrm{d}^{4}(\mathbf{1})$ and 

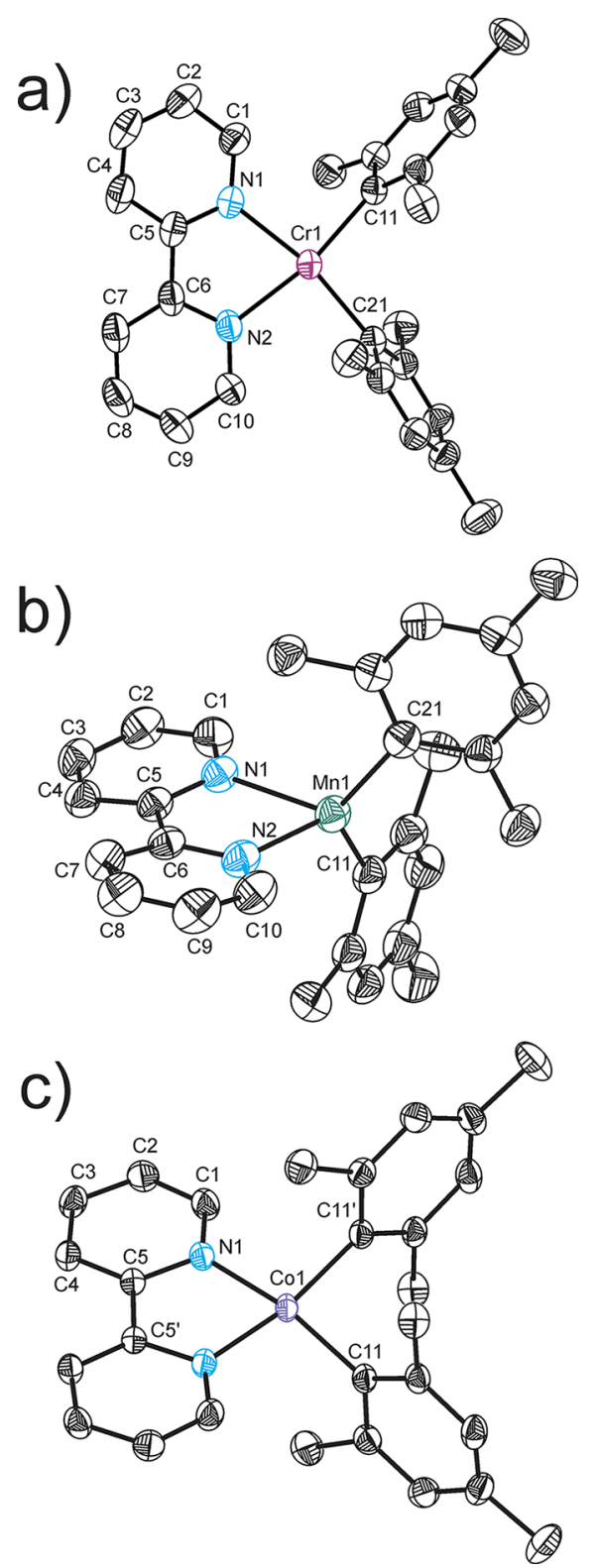

Figure 2. Thermal ellipsoid plots of (a) $1 \cdot 1.5 \mathrm{C}_{6} \mathrm{H}_{6}$, (b) 2, and (c) 4.THF (only crystallographically unique positions are labeled; positions labeled with a prime symbol are related by $0.5-x, 0.5-$ $y, z$ ). All solvent and hydrogen atoms have been omitted for clarity. Anisotropic displacement ellipsoids are pictured at the 50\% probability level.

$\mathrm{d}^{8}$ (5) configurations would be anticipated on the basis of ligand-field arguments, as would the adoption of pseudotetrahedral structures for $\mathrm{d}^{5}(2)$ and $\mathrm{d}^{6}(3) .{ }^{32} \mathrm{DFT}$ calculations (vide infra) suggest that the pseudo-square-planar and pseudotetrahedral geometries are very close in energy for the cobalt system 4 , the marginal preference for the former being due to the relatively strong ligand field imposed by the mesityl groups. The adoption of square-planar geometries for complexes of $\mathrm{Co}(\mathrm{II})$ has precedent in the literature. ${ }^{33}$

Across the series of complexes $\left[\mathrm{M}\left(2,2^{\prime}\right.\right.$-bipy $\left.)(\mathrm{mes})_{2}\right](\mathrm{M}=$ $\mathrm{Cr}$ (1), Mn (2), Fe (3), Co (4), Ni (5)) there are significant variations in both the $\mathrm{M}-\mathrm{C}$ and $\mathrm{M}-\mathrm{N}$ bond distances (Figure 3). Moving from $1(\mathrm{Cr})$ to $2(\mathrm{Mn})$, the switch from pseudosquare-planar to pseudo-tetrahedral geometry results in population of orbitals with significant $\mathrm{M}-\mathrm{C}$ and $\mathrm{M}-\mathrm{N}$
Table 1. Selected X-ray Data Collection and Refinement Parameters for $1 \cdot 1.5 \mathrm{C}_{6} \mathrm{H}_{6}, 2$, and $4 \cdot \mathrm{THF}$

\begin{tabular}{|c|c|c|c|}
\hline compd & $1 \cdot 1.5 \mathrm{C}_{6} \mathrm{H}_{6}$ & 2 & 4.THF \\
\hline formula & $\mathrm{C}_{37} \mathrm{H}_{39} \mathrm{CrN}_{2}$ & $\mathrm{C}_{28} \mathrm{H}_{30} \mathrm{MnN}_{2}$ & $\mathrm{C}_{32} \mathrm{H}_{38} \mathrm{CoN}_{2} \mathrm{C}$ \\
\hline fw & 563.70 & 449.48 & 525.57 \\
\hline cryst syst & monoclinic & monoclinic & orthorhombic \\
\hline space group & $\mathrm{C} 2 / \mathrm{c}$ & $P 2_{1} / c$ & $P c c n$ \\
\hline$a(\AA)$ & $27.8996(2)$ & $12.0845(5)$ & $10.7358(1)$ \\
\hline$b(\AA)$ & $13.1692(1)$ & $13.8358(6)$ & $14.5102(1)$ \\
\hline$c(\AA)$ & $18.3471(2)$ & $14.8944(6)$ & $17.9942(1)$ \\
\hline \multicolumn{4}{|l|}{$\alpha(\operatorname{deg})$} \\
\hline$\beta(\operatorname{deg})$ & $110.830(1)$ & $102.445(2)$ & \\
\hline \multicolumn{4}{|l|}{$\gamma(\operatorname{deg})$} \\
\hline$V\left(\AA^{3}\right)$ & $6300.41(10)$ & $2431.81(18)$ & $2803.11(4)$ \\
\hline$Z$ & 8 & 4 & 4 \\
\hline radiation, $\lambda(\AA)$ & $\begin{array}{l}\text { Mo K } \alpha \text {, } \\
0.71073\end{array}$ & $\begin{array}{l}\text { Mo K } \alpha \text {, } \\
0.71073\end{array}$ & $\begin{array}{l}\text { Mo K } \alpha \text {, } \\
0.71073\end{array}$ \\
\hline$T(\mathrm{~K})$ & $150(2)$ & $150(2)$ & $150(2)$ \\
\hline$\rho_{\text {calcd }}\left(\mathrm{g} \mathrm{cm}^{-3}\right)$ & 1.189 & 1.228 & 1.245 \\
\hline$\mu\left(\mathrm{mm}^{-1}\right)$ & 0.390 & 0.559 & 0.638 \\
\hline no. of rflns collected & 13529 & 7742 & 60428 \\
\hline no. of indep rflns & 7151 & 4207 & 3192 \\
\hline no. of params & 387 & 280 & 174 \\
\hline$R$ (int) & 0.0226 & 0.0513 & 0.0400 \\
\hline $\mathrm{R} 1 / \mathrm{wR} 2,^{a} I \geq 2 \sigma_{I}(\%)$ & $4.68 / 12.53$ & $5.16 / 13.20$ & $4.37 / 12.50$ \\
\hline $\mathrm{R} 1 / \mathrm{wR} 2{ }^{a}$, all data $(\%)$ & $5.85 / 13.46$ & $7.40 / 14.34$ & $5.04 / 13.16$ \\
\hline GOF & 1.037 & 1.032 & 1.064 \\
\hline
\end{tabular}

${ }^{a} \mathrm{R} 1=\left[\sum\left\|F_{\mathrm{o}}|-| F_{c}\right\|\right] / \sum\left|F_{\mathrm{o}}\right| ; w \mathrm{R} 2=\left\{\left[\sum w\left[\left(F_{\mathrm{o}}\right)^{2}-\left(F_{\mathrm{c}}\right)^{2}\right]^{2}\right] /\right.$ $\left.\left[\sum w\left(F_{\mathrm{o}}\right)^{2}\right]\right\}^{1 / 2} ; w=\left[\sigma^{2}\left(F_{\mathrm{o}}\right)^{2}+(A P)^{2}+B P\right]^{-1}$, where $P=\left[\left(F_{\mathrm{o}}\right)^{2}+\right.$ $\left.2\left(\mathrm{~F}_{\mathrm{c}}\right)^{2}\right] / 3$ and the $A$ and $B$ values are respectively 0.0711 and 3.82 for $1 \cdot 1.5 \mathrm{C}_{6} \mathrm{H}_{6}, 0.0731$ and 0.92 for 2 , and 0.0762 and 2.07 for $4 \cdot \mathrm{THF}$.

antibonding character, as a result of which both $\mathrm{M}-\mathrm{C}$ and $\mathrm{M}-\mathrm{N}$ bonds elongate. The increase of effective nuclear charge from 2 to $3(\mathrm{Fe})$ then results in a contraction of $\sim 0.07 \AA$ in both $\mathrm{M}-\mathrm{C}$ and $\mathrm{M}-\mathrm{N}$ bonds within a constant pseudotetrahedral environment. The sharp contraction for $\mathbf{4}$ and $\mathbf{5}$ reflects a switch back to pseudo-square-planar coordination, the values being lower than those for $\mathbf{1}$ due to the substantial contraction in metal radius from $\mathrm{Cr}$ to $\mathrm{Co}$ and $\mathrm{Ni}$. In marked contrast, the bond lengths within the 2,2'-bipy ligand units are almost invariant across the series, suggesting that back-bonding is indeed limited, as argued by Wieghardt. ${ }^{15}$

The chemical reduction of $\mathbf{1 - 5}$ with 1 equiv of potassium metal in the presence of suitable cation sequestering agents was found to yield salts of the anionic species [M(2,2'-bipy)$\left.(\mathrm{mes})_{2}\right]^{-}\left(\mathrm{M}=\mathrm{Cr}\left(\mathbf{1}^{-}\right), \mathrm{Mn}\left(\mathbf{2}^{-}\right)\right.$, Fe $\left(3^{-}\right)$, Co $\left.\left(4^{-}\right), \mathrm{Ni}\left(\mathbf{5}^{-}\right)\right)$ in varying crystalline yields. These species were crystallographically characterized in [K(dibenzo-18-crown-6).THF]-

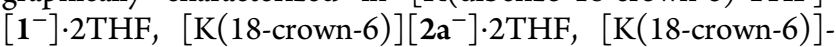
$\left[\mathbf{2 b}^{-}\right] \cdot 0.67 \mathrm{py} \cdot 0.67 \mathrm{tol}, \quad[\mathrm{K}(2,2,2$-crypt $)]\left[\mathbf{4}^{-}\right]$, and $[\mathrm{K}(2,2,2-$ crypt) $]\left[5^{-}\right]$(Figure 4 ). The iron analogue was previously characterized in $[\mathrm{K}(2,2,2$-crypt $)]\left[3^{-}\right] .^{17}$ Crystallographic data and experimental parameters for the structures are presented in Table 2. The coordination geometries of the anionic species $\left[\mathrm{M}\left(2,2^{\prime} \text {-bipy }\right)(\mathrm{mes})_{2}\right]^{-}$are very similar to those of their neutral analogues. Thus, $\mathbf{1}^{-}, 4^{-}$, and $5^{-}(\mathrm{M}=\mathrm{Cr}, \mathrm{Co}, \mathrm{Ni})$ retain distorted-square-planar geometries $\left(\phi=22.7,4.2\right.$, and $5.3^{\circ}$, respectively) while $2^{-}$and $3^{-}$have a pseudo-tetrahedral geometry $\left(81.9\right.$ or $82.3^{\circ}$ for the $2 \mathbf{a}^{-}$and $2 \mathbf{b}^{-}$solvates, respectively, and $78.6^{\circ}$ for $\left.3^{-}\right) .^{17}$ In 2 and 3 , reduction therefore appears to shift the structure toward a more tetrahedral geometry. The trends in $\mathrm{M}-\mathrm{C}$ and $\mathrm{M}-\mathrm{N}$ bond 

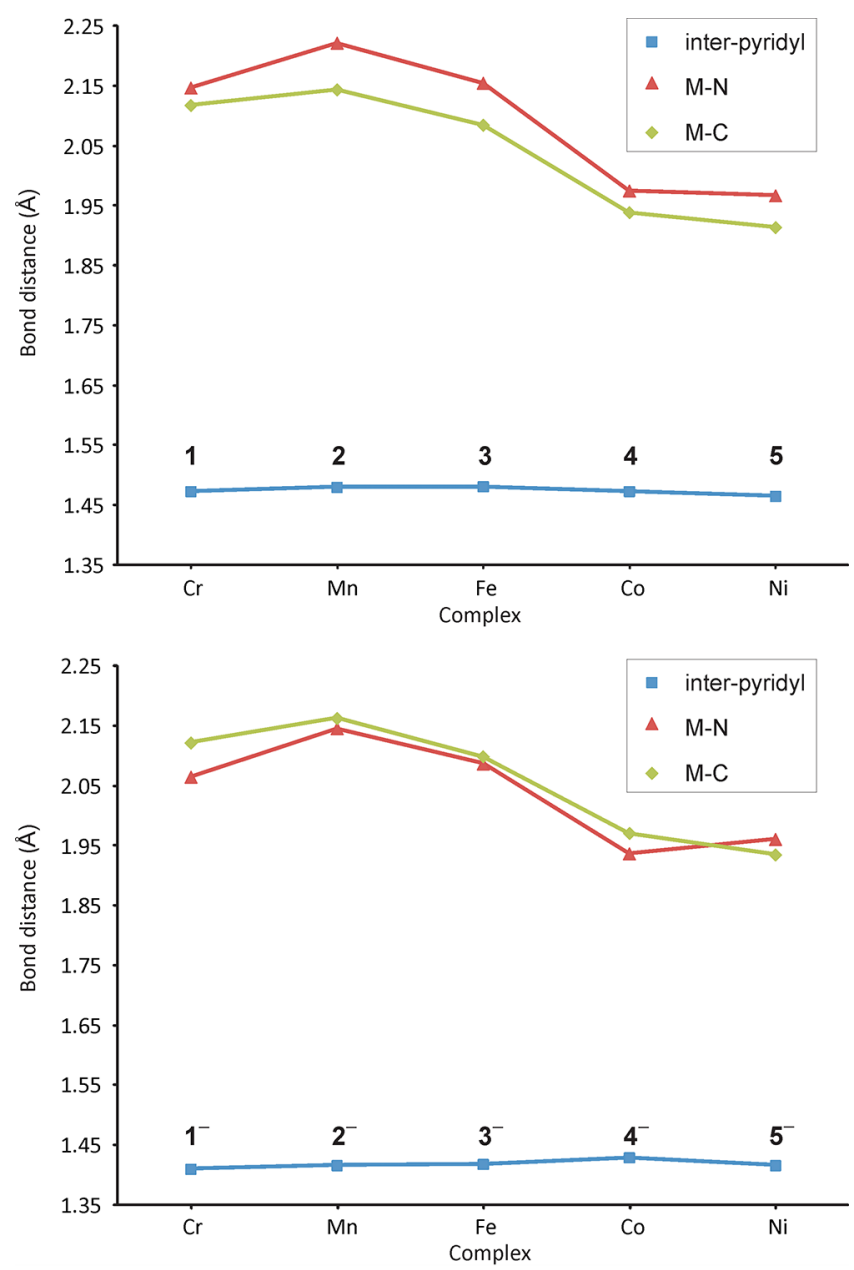

Figure 3. Variations in interatomic distances for the neutral complexes 1-5 (top) and anionic complexes $\mathbf{1}^{-}-5^{-}$(bottom). Data for $3 / 3^{-}$and 5 are taken from refs 17 and 21 , respectively.

lengths across the anionic series follow closely those noted above for the neutral parents (Figure 3). Thus, the $\mathrm{M}-\mathrm{C}$ and $\mathrm{M}-\mathrm{N}$ bond lengths elongate from $\mathbf{1}^{-}$to $2^{-}$, reflecting the switch in coordination geometry, and then contract from $2^{-}$to $3^{-}$, reflecting the differing ionic radii of $\mathrm{Mn}(\mathrm{II})$ and $\mathrm{Fe}(\mathrm{II}) . \mathrm{A}$ sharp contraction from $3^{-}$to $4^{-}$and $5^{-}$marks the return to pseudo-square-planar coordination.

On comparison of the neutral and anionic series (Table 3), it is clear that, while the $\mathrm{M}-\mathrm{C}$ bond lengths are relatively unaffected by reduction $\left(0.032 \AA\right.$ for 4 to $4^{-}$being the largest shift), the $\mathrm{M}-\mathrm{N}$ bond lengths vary more significantly. In the earlier transition metals $(\mathrm{Cr}, \mathrm{Mn}, \mathrm{Fe})$, reduction causes a contraction of $\sim 0.07 \AA$, while in the Co and $\mathrm{Ni}$ analogues the changes are less striking. Indeed in the case of $\mathbf{5}$ and $\mathbf{5}^{-}$, the $\mathrm{M}-\mathrm{N}$ bond lengths are almost identical. The bond lengths within the bipyridyl ligand are again relatively constant across the anionic series but are dramatically different from those of the neutral analogues. The $\mathrm{C}-\mathrm{C}$ bond linking the two rings, in particular, is $\sim 0.06 \AA$ shorter in the anions, a clear indication of the population of the LUMO of neutral bipyridine. We return to these structural trends following the discussion of electronic structure.

Magnetism and Spectroscopy. Complexes 1-4 and all of the anionic moieties $\mathbf{1}^{-}-5^{-}$were found to be paramagnetic. The magnetic behavior of these species was studied using
SQUID magnetometry in an effort to shed further light on the formal oxidation states of ligands and metal ions. During the synthesis of the anionic complexes we found it was very difficult, despite extensive precautions, to avoid formation of trace amounts of ferromagnetic decomposition products. The presence of such impurities was detected by performing variable field isothermal magnetization measurements. Where present, the response of the impurities was distinguished from that of the complex itself by measuring the gradient of the linear portion of the magnetization vs field curve.

Samples of the neutral complexes 1-4 were cooled to $2 \mathrm{~K}$ in zero field and the magnetic susceptibility measured between 2 and $300 \mathrm{~K}$ in an applied field of 0.01 or $0.02 \mathrm{~T}$. The samples were subsequently cooled to $2 \mathrm{~K}$ in an applied field, and the magnetic susceptibility was measured. The zero-field-cooled (ZFC) and field-cooled (FC) results were virtually identical and have been merged. The magnetic behavior of the neutral complexes 1, 2, and $\mathbf{4}$ is shown in Figure 5a and is largely in line with what might be expected for paramagnetic organometallic complexes with weak or no spin-orbit coupling. Fitting to the Curie-Weiss law

$$
\chi_{\mathrm{mol}}=\frac{N_{\mathrm{A}} \mu_{0} \mu_{\mathrm{B}}^{2} S(S+1)}{3 k} \frac{g^{2}}{T-\Theta}+\chi_{\mathrm{TIM}}
$$

where $\chi_{\text {TIM }}$ is the temperature-independent magnetism term, leads to the values of $g, \Theta$, and $\chi_{\text {TIM }}$ summarized in Table 4 . Fitting to the three-parameter equation (1) $\left(g, \theta, \chi_{\text {TIM }}\right)$ was performed using the simplex algorithm to locate the global

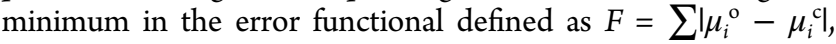
where $\mu_{i}^{\mathrm{o}}$ and $\mu_{i}^{\mathrm{c}}$ are the observed and calculated effective magnetic moments, respectively. Due to a combination of factors, the fits are not exact, and the term $\chi_{\text {TIM }}$ in eq 1 probably captures a number of contributions, including (i) the contribution of excited electronic states-the intrinsic temperature-independent paramagnetism (TIP), (ii) approximations in the estimation of the diamagnetic component from Pascal's constants, (iii) the uncompensated contribution of the sample container, and (iv) the contribution of traces of ferromagnetic impurities. Nevertheless, the best-fit parameters are sufficiently accurate to give an indication of the number of unpaired electrons and therefore, in the case of the anions, the nature of the coupling between metal- and ligand-based spin densities.

The $g$ values for chromium(II) (1) and manganese(II) (2) lie within the expected ranges for related complexes, while that for the cobalt(II) complex $\mathbf{4}$ is rather large, consistent with a significant contribution of the orbital angular momentum. An additional complicating factor may arise due to the fact that crystals of $\mathbf{4}$ were found to undergo rather extensive changes to the lattice parameters on varying the temperature (see the Supporting Information for details). While this phenomenon has no major effect on the coordination environment of the cobalt center, there are notable changes to intermolecular distances which could give rise to small variations to exchange interactions between adjacent molecules. That being said, the small and negative values of Weiss constants observed for all three complexes are in agreement with expected negligible intermolecular interactions.

The magnetic measurements for the anionic systems $\left[\mathrm{K}\left(\right.\right.$ dibenzo-18-crown-6)][1 $\left.\mathbf{1}^{-}\right]$and $\left[\mathrm{K}(18\right.$-crown-6) $]\left[\mathbf{2}^{-}\right]$are consistent with the presence of $\mathrm{M}(\mathrm{II})$ metal centers $(S=2$ and $S=5 / 2$, respectively) that are strongly antiferromagnetically coupled to a ligand radical, $S=1 / 2$ (Figure $5 b$ ). The isotropic 

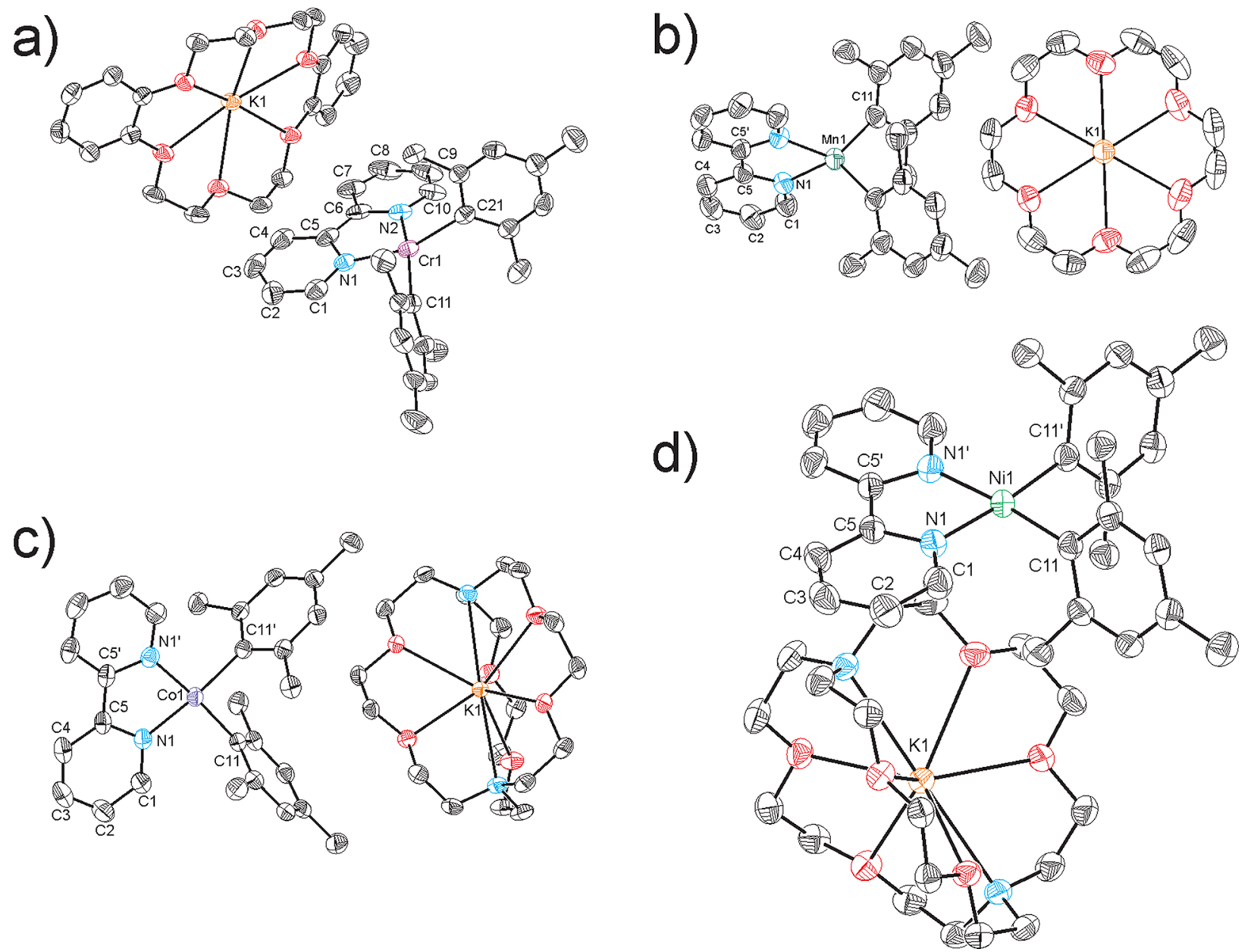

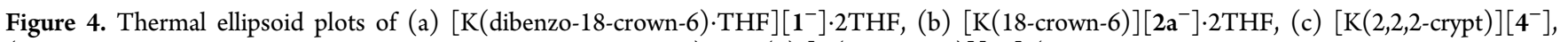
(positions labeled with a prime symbol are related by $+y,+x, 2-z)$, and $(\mathrm{d})\left[\mathrm{K}(2,2,2\right.$-crypt) $]\left[5^{-}\right]$(positions labeled with a prime symbol are related by $+y,+x,-z)$. All solvent molecules and hydrogen atoms have been omitted for clarity. Anisotropic displacement ellipsoids are pictured at the $50 \%$ probability level.

exchange can be described by the Heisenberg spin Hamiltonian:

$$
\hat{H}=-J\left(\vec{S}_{1} \cdot \vec{S}_{2}\right)+\sum_{i=1}^{2} \mu_{\mathrm{B}} B g_{i} \hat{S}_{i, z}
$$

An antiferromagnetic interaction between a $\mathrm{M}(\mathrm{II})$ center with spin $S_{1}$ and a $2,2^{\prime}$-bipy radical spin, $S_{2}=1 / 2$, results in a ground spin state $S_{\min }=\left|S_{1}-S_{2}\right|$ with an excited state $S_{\max }=S_{1}+S_{2}$ lying $\Delta=-J / 2\left[S_{\max }\left(S_{\max }+1\right)-S_{\min }\left(S_{\min }+1\right)\right]$ higher in energy. For $1^{-}, 2^{-}$, and $4^{-}, \Delta=-2.5 J,-3 J$, and $-2 J$, respectively. For $\mathbf{1}^{-}$and $2^{-}$, the antiferromagnetic interaction is so strong $\left(J<-350 \mathrm{~cm}^{-1}\right)$ that the $S_{\text {min }}$ ground state is effectively isolated and the effective magnetic moment remains almost constant over the 50-300 $\mathrm{K}$ temperature range. These results are supported by DFT calculations (vide infra), which gave computed $J$ values of -508 and $-492 \mathrm{~cm}^{-1}$ for $\mathbf{1}^{-}$and $2^{-}$, respectively (using the spin Hamiltonian in eq 2). Therefore, the magnetic data were fitted to the Curie-Weiss law for $S=$ $S_{\text {min }}$ (eq 1), yielding the parameters collected in Table 4 . The Weiss constants are somewhat smaller than those of the corresponding neutral species. Attempts to fit the data to a spin Hamiltonian containing a single-ion zero-field splitting anisotropy term led to unphysically large values of $D_{\mathrm{Cr}}$ and
$D_{\mathrm{Mn}}$, suggesting that intermolecular exchange interactions are the likeliest source of the deviations from ideal Curie behavior.

The magnetic behavior of the anionic cobalt complex $4^{-}$is rather more complex than that of either $1^{-}$or $2^{-}$. The moment varies between $\sim 1.15$ (at $20 \mathrm{~K}$ ) and $1.88 \mu_{\mathrm{B}}$ (at $300 \mathrm{~K}$ ) across the accessible temperature range, values that lie intermediate between spin-only values for singlet and triplet states, probably reflecting again the contribution of orbital angular momentum in the cobalt(II) ion. Finally, no magnetic exchange is present in complex $5^{-}$between diamagnetic nickel(II) and bipy radical. Accordingly, the low-temperature value of $\mu_{\text {eff }} / \mu_{\mathrm{B}}=1.51$ (at 20 $\mathrm{K})$ is close to the theoretical value of 1.73 for $S=1 / 2$ and $g=$ 2.0: the decrease at high temperatures may again be due to the presence of unsaturated trace impurities.

Electronic Structure Trends across the $\left[M\left(2,2^{\prime}\right.\right.$-bipy)$\left.(\mathrm{mes})_{2}\right]^{0 /-}(\mathrm{M}=\mathrm{Cr}-\mathrm{Ni})$ Series. Following our published discussion of the electronic structure of the $\left[\mathrm{Fe}^{\mathrm{II}}\left(2,2^{\prime}-\right.\right.$ bipy)(mes) $\left.)_{2}\right]^{0 /-}$ complexes, ${ }^{17}$ we are now in a position to analyze periodic variations in the electron density distribution across the entire series of the neutral parent complexes $\left[\mathrm{M}\left(2,2^{\prime}\right.\right.$-bipy $\left.)(\mathrm{mes})_{2}\right]$ and their anions $(\mathrm{M}=\mathrm{Cr}, \mathrm{Mn}, \mathrm{Fe}, \mathrm{Co}$, $\mathrm{Ni}$ ). The optimized geometries of all of the complexes are summarized in Table 5 (the iron complexes described in ref 17 are included for completeness). Although absolute values of the metal-ligand bond lengths are somewhat larger than the 
Table 2. Selected X-ray Data Collection and Refinement Parameters for $\left[\mathrm{K}(\right.$ dibenzo-18-crown-6) $\cdot \mathrm{THF}]\left[1^{-}\right] \cdot 2 \mathrm{THF},[\mathrm{K}(18-$

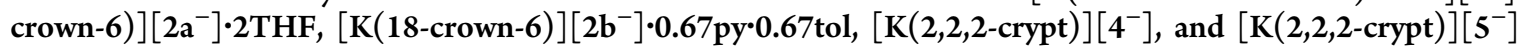

\begin{tabular}{|c|c|c|c|c|c|}
\hline compd & $\begin{array}{c}{[\mathrm{K}(\text { dibenzo-18-crown-6) } \mathrm{THF}]} \\
{\left[\mathbf{1}^{-}\right] \cdot 2 \mathrm{THF}}\end{array}$ & $\begin{array}{c}{[\mathrm{K}(18-\text { crown }-6)]} \\
{\left[2 \mathrm{a}^{-}\right] \cdot 2 \mathrm{THF}}\end{array}$ & $\begin{array}{c}{\left[\mathrm{K}(18 \text {-crown-6) }]\left[2 \mathbf{b}^{-}\right]\right.} \\
0.67 \mathrm{py} \cdot 0.67 \mathrm{tol}\end{array}$ & {$[\mathrm{K}(2,2,2$-crypt $)]$} & $\frac{[\mathrm{K}(2,2,2 \text {-crypt })]}{\left[\mathbf{5}^{-}\right]}$ \\
\hline formula & $\mathrm{C}_{60} \mathrm{H}_{78} \mathrm{CrK} \mathrm{N} \mathrm{N}_{2} \mathrm{O}_{9}$ & $\mathrm{C}_{48} \mathrm{H}_{70} \mathrm{KMnN}_{2} \mathrm{O}_{8}$ & $\mathrm{C}_{48} \mathrm{H}_{62.67} \mathrm{KMnN}_{2.67} \mathrm{O}_{6}$ & $\mathrm{C}_{46} \mathrm{H}_{66} \mathrm{CoKN}_{4} \mathrm{O}_{6}$ & $\mathrm{C}_{46} \mathrm{H}_{66} \mathrm{KN}_{4} \mathrm{NiO}_{6}$ \\
\hline $\mathrm{fw}$ & 1062.34 & 897.10 & 867.05 & 869.06 & 868.84 \\
\hline cryst syst & monoclinic & orthorhombic & monoclinic & tetragonal & tetragonal \\
\hline space group & $P 2_{1} / c$ & $F d d 2$ & $\mathrm{C} 2 / \mathrm{c}$ & $P 4_{1} 2_{1} 2$ & $P 4_{3}{ }_{1} 2$ \\
\hline$a(\AA)$ & $14.2207(2)$ & $13.0840(2)$ & $13.3060(1)$ & $12.8822(1)$ & $12.9305(2)$ \\
\hline$b(\AA)$ & $13.7416(2)$ & $32.1910(4)$ & $24.1421(2)$ & & \\
\hline$c(\AA)$ & $29.9804(5)$ & $23.1510(3)$ & $43.8747(4)$ & $27.3451(2)$ & $27.1526(8)$ \\
\hline \multicolumn{6}{|l|}{$\alpha(\mathrm{deg})$} \\
\hline$\beta(\mathrm{deg})$ & $107.561(1)$ & & $94.833(1)$ & & \\
\hline \multicolumn{6}{|l|}{$\gamma(\operatorname{deg})$} \\
\hline$V\left(\AA^{3}\right)$ & $5585.59(15)$ & $9750.9(2)$ & $14044.0(2)$ & $4537.95(6)$ & $4539.86(17)$ \\
\hline$Z$ & 4 & 8 & 12 & 4 & 4 \\
\hline radiation, $\lambda(\AA)$ & Mo $\mathrm{K} \alpha, 0.71073$ & synchrotron, 0.68890 & Mo K $\alpha, 0.71073$ & Mo $\mathrm{K} \alpha, 0.71073$ & Mo $\mathrm{K} \alpha, 0.71073$ \\
\hline$T(\mathrm{~K})$ & $150(2)$ & $150(2)$ & $150(2)$ & $150(2)$ & $150(2)$ \\
\hline$\rho_{\text {calcd }}\left(\mathrm{g} \mathrm{cm}^{-3}\right)$ & 1.263 & 1.222 & 1.230 & 1.272 & 1.271 \\
\hline$\mu\left(\mathrm{mm}^{-1}\right)$ & 0.337 & 0.407 & 0.419 & 0.520 & 0.569 \\
\hline no. of rflns collected & 18045 & 10294 & 20840 & 10324 & 10334 \\
\hline no. of indep rflns & 9745 & 4039 & 12268 & 5171 & 5176 \\
\hline no. of params & 695 & 300 & 794 & 263 & 263 \\
\hline$R($ int $)$ & 0.0399 & 0.0630 & 0.0246 & 0.0158 & 0.0228 \\
\hline $\mathrm{R} 1 / \mathrm{wR} 2,{ }^{a} I \geq 2 \sigma_{I}(\%)$ & $5.04 / 11.28$ & $4.32 / 10.89$ & $4.44 / 9.31$ & $2.81 / 7.18$ & $3.38 / 7.98$ \\
\hline $\mathrm{R} 1 / \mathrm{wR} 2{ }^{a}{ }^{a}$ all data (\%) & $8.89 / 12.46$ & $5.07 / 11.56$ & $7.52 / 10.40$ & $3.29 / 7.38$ & $4.23 / 8.39$ \\
\hline GOF & 0.996 & 1.063 & 1.017 & 1.025 & 1.027 \\
\hline
\end{tabular}

${ }^{a} \mathrm{R} 1=\left[\sum\left\|F_{\mathrm{o}}|-| F_{\mathrm{c}}\right\|\right] / \sum\left|F_{\mathrm{o}}\right| ; \mathrm{wR} 2=\left\{\left[\sum w\left[\left(F_{\mathrm{o}}\right)^{2}-\left(F_{\mathrm{c}}\right)^{2}\right]^{2}\right] /\left[\sum w\left(F_{\mathrm{o}}{ }^{2}\right)^{2}\right]\right\}^{1 / 2} ; \mathrm{w}=\left[\sigma^{2}\left(F_{\mathrm{o}}\right)^{2}+(A P)^{2}+B P\right]^{-1}$, where $P=\left[\left(\mathrm{F}_{\mathrm{o}}\right)^{2}+2\left(F_{\mathrm{c}}\right)^{2}\right] / 3$ and the

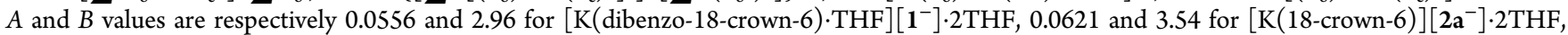

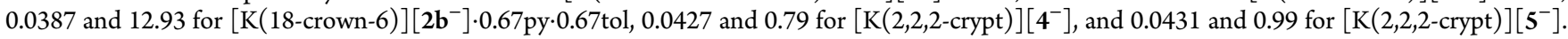

experimental lengths, the optimized structural parameters reproduce the key trends identified previously in the structural data. The $\mathrm{Cr}$, $\mathrm{Co}$, and $\mathrm{Ni}$ complexes $\left(1 / \mathbf{1}^{-}, 4 / 4^{-}\right.$, and $5 / 5^{-}$, respectively) are all approximately square planar, while their $\mathrm{Mn}$ and $\mathrm{Fe}$ counterparts approach the idealized tetrahedral limit. The much shorter $\mathrm{C}-\mathrm{C}$ bonds in the reduced species are apparent in the computed structures, as is the tendency for both $\mathrm{M}-\mathrm{N}$ and $\mathrm{C}-\mathrm{C}$ bonds to contract upon reduction. This trend is most striking in the earlier transition metals, although the contraction in $\mathrm{M}-\mathrm{N}$ bonds is smaller in magnitude than that observed experimentally while the $\mathrm{M}-\mathrm{C}$ bonds elongate somewhat upon reduction (in comparison to the almost invariant bond lengths observed in the X-ray data). This suggests a somewhat unbalanced description of $\mathrm{M}-\mathrm{N}$ and $\mathrm{M}-$ $\mathrm{C}$ bonding, but nevertheless the basic trends in electronic structure appear well reproduced. The net Mulliken spin densities on the $2,2^{\prime}$-bipy ligands in the anionic species confirm the presence of $2,2^{\prime}$-bipy radicals anions in all cases (see Figure 6 for spin density plots for $1 / 1^{-}$and $2 / 2^{-}$). In the case of antiferromagnetic coupling $\left(1^{-}, 2^{-}, 3^{-}, 4_{\mathrm{td}}^{-}\right)$, spin contamination leads to values of $\left\langle S^{2}\right\rangle$ of approximately $S(S+1)+1.0$ (in the limit of weak overlap, $S^{2}=S(S+1)+N_{\beta}$, where $N_{\beta}$ is the number of unpaired electrons of $\beta$ spin (in these cases 1)). ${ }^{34}$

The trends in magnetic susceptibility can be understood within the framework of two structurally distinct classes, the approximately square planar complexes $\mathbf{1}, \mathbf{4}$, and $\mathbf{5}$ together with their anionic derivatives, and the approximately tetrahedral $2 / 2^{-}$and $3 / 3^{-}$. For $2^{-}$and $3^{-}$, the very strong antiferromagnetic coupling arises from the strong overlap of the singly occupied $\pi^{*}$ orbital on the $2,2^{\prime}$-bipy radical with the metal $\mathrm{d}_{x z}$ orbital, which also carries significant $\mathrm{M}-\mathrm{C}$ antibonding character. The computed exchange coupling constants, $J$, are both very large and negative, consistent with the experimental measurements that identify an upper limit of $\sim-350 \mathrm{~cm}^{-1}$. We note here that the Heisenberg Hamiltonian is not strictly applicable in the Fe case, where the iron(II) ion, in the limit of perfect $T_{d}$ symmetry, is orbitally degenerate. Nevertheless, it is clear that the antiferromagnetically coupled $S$ $=3 / 2$ state is significantly more stable than its $S=5 / 2$ counterpart.

In the approximately square planar case of $\mathbf{1}^{-}$, all four lowlying metal d orbitals are singly occupied, and so the electron in the $\pi^{*}$ orbital of the 2,2'-bipy radical is again antiferromagnetically coupled to the metal, this time through the approximately nonbonding $\mathrm{d}_{x z}$ orbital. In the $\mathrm{Ni}$ analogue $5^{-}$, all four low-lying orbitals on the metal are now doubly occupied, and so the exchange coupling is necessarily zero. The structural preferences for the $\mathrm{d}^{7}$ metal center in $\mathbf{4}$ and $\mathbf{4}^{-}$are less clear-cut, and there is precedent in the literature for both tetrahedral and square-planar geometries. For the neutral compound $\mathbf{4}$ we have identified minima corresponding to both pseudo-tetrahedral and pseudo-square-planar isomers (with $S=3 / 2$ and $1 / 2$, respectively), the latter being preferred by $4 \mathrm{kcal} \mathrm{mol}^{-1}$, consistent with the $\mathrm{X}$-ray structure. The anion presents a more complicated picture, due to the possibility of ferro- or antiferromagnetic coupling between Co- and bipy-based electrons. In the pseudo-tetrahedral case $4_{\mathrm{td}}{ }^{-}$the dominant exchange coupling pathway is qualitatively identical with that in $2^{-}$and $3^{-}$(bipy $\pi^{*}$ with singly occupied metal $d_{x z}$ ), resulting in strong antiferromagnetic coupling and therefore a triplet ground state. In the low-spin pseudo-square-planar form $4_{\mathrm{sp}}{ }^{-}$, 
Table 3. Selected Interatomic Distances and Angles for the Neutral and Anionic Species Crystallographically Characterized in

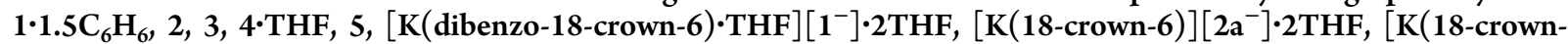
$6)]\left[2 \mathrm{~b}^{-}\right] \cdot 0.67 \mathrm{py} \cdot 0.67 \mathrm{tol},[\mathrm{K}(2,2,2$-crypt $)]\left[4^{-}\right]$, and $[\mathrm{K}(2,2,2$-crypt $)]\left[5^{-}\right]$

\begin{tabular}{|c|c|c|c|c|c|c|c|c|c|c|}
\hline & \multicolumn{2}{|c|}{$\mathrm{M}=\mathrm{Cr}$} & \multicolumn{2}{|c|}{$\mathrm{M}=\mathrm{Mn}$} & \multicolumn{2}{|c|}{$\mathrm{M}=\mathrm{Fe}$} & \multicolumn{2}{|c|}{$\mathrm{M}=\mathrm{Co}$} & \multicolumn{2}{|c|}{$\mathrm{M}=\mathrm{Ni}$} \\
\hline & 1 & $1^{-}$ & 2 & $2 a^{-} / 2 b^{-}$ & $3^{a}$ & $3^{-a}$ & 4 & $4^{-}$ & $5^{b}$ & $5^{-}$ \\
\hline \multicolumn{11}{|c|}{ Bond Lengths $(\AA)$} \\
\hline $\mathrm{C} 5-\mathrm{C} 6$ & $1.473(3)$ & $1.410(4)$ & $1.480(4)$ & $\begin{array}{l}1.422(6) \\
/ 1.409(\mathrm{av})\end{array}$ & $1.479(3)$ & $1.418(3)$ & $1.473(4)$ & $1.429(4)$ & $1.465(4)$ & $1.416(4)$ \\
\hline $\mathrm{N} 1-\mathrm{C} 1 / \mathrm{N} 2-\mathrm{C} 10$ & $1.342(\mathrm{av})$ & $1.361(\mathrm{av})$ & $1.344(\mathrm{av})$ & $\begin{array}{l}1.337(4) \\
/ 1.352(\mathrm{av})\end{array}$ & $1.343(\mathrm{av})$ & $1.356(\mathrm{av})$ & $1.345(3)$ & $1.364(2)$ & $1.343(\mathrm{av})$ & $1.354(3)$ \\
\hline $\mathrm{N} 1-\mathrm{C} 5 / \mathrm{N} 2-\mathrm{C} 6$ & $1.359(\mathrm{av})$ & 1.390 (av) & $1.349(\mathrm{av})$ & $\begin{array}{l}1.381(4) \\
/ 1.390(\mathrm{av})\end{array}$ & $1.351(\mathrm{av})$ & $1.386(\mathrm{av})$ & $1.363(2)$ & $1.382(2)$ & $1.359(\mathrm{av})$ & $1.390(2)$ \\
\hline $\mathrm{C} 1-\mathrm{C} 2 / \mathrm{C} 9-\mathrm{C} 10$ & $1.384(\mathrm{av})$ & $1.361(\mathrm{av})$ & $1.383(\mathrm{av})$ & $\begin{array}{l}1.374(5) \\
/ 1.362(\mathrm{av})\end{array}$ & $1.380(\mathrm{av})$ & $1.372(\mathrm{av})$ & $1.382(3)$ & $1.369(3)$ & $1.382(\mathrm{av})$ & $1.378(3)$ \\
\hline $\mathrm{C} 2-\mathrm{C} 3 / \mathrm{C} 8-\mathrm{C} 9$ & $1.379(\mathrm{av})$ & $1.403(\mathrm{av})$ & $1.378(\mathrm{av})$ & $\begin{array}{l}1.396(5) \\
/ 1.409(\mathrm{av})\end{array}$ & $1.381(\mathrm{av})$ & $1.400(\mathrm{av})$ & $1.382(3)$ & $1.401(3)$ & $1.372(\mathrm{av})$ & $1.400(4)$ \\
\hline $\mathrm{C} 3-\mathrm{C} 4 / \mathrm{C} 7-\mathrm{C} 8$ & $1.380(\mathrm{av})$ & $1.357(\mathrm{av})$ & $1.379(\mathrm{av})$ & $\begin{array}{l}1.349(5) \\
/ 1.354(\mathrm{av})\end{array}$ & $1.380(\mathrm{av})$ & $1.359(\mathrm{av})$ & $1.382(3)$ & $1.364(3)$ & $1.380(\mathrm{av})$ & $1.360(3)$ \\
\hline $\mathrm{C} 4-\mathrm{C} 5 / \mathrm{C} 6-\mathrm{C} 7$ & $1.388(\mathrm{av})$ & $1.414(\mathrm{av})$ & $1.390(\mathrm{av})$ & $\begin{array}{l}1.416(4) \\
/ 1.422(\mathrm{av})\end{array}$ & $1.393(\mathrm{av})$ & $1.419(\mathrm{av})$ & $1.382(2)$ & $1.408(2)$ & $1.386(\mathrm{av})$ & $1.419(3)$ \\
\hline $\mathrm{M}-\mathrm{N} 1 / \mathrm{M}-\mathrm{N} 2$ & $2.147(\mathrm{av})$ & $2.065(\mathrm{av})$ & $2.222(\mathrm{av})$ & $\begin{array}{l}2.141(2) \\
/ 2.150(\mathrm{av})\end{array}$ & $2.155(\mathrm{av})$ & $2.087(\mathrm{av})$ & $1.975(2)$ & $1.937(1)$ & $1.967(\mathrm{av})$ & $1.961(2)$ \\
\hline $\mathrm{M}-\mathrm{C} 11 / \mathrm{M}-\mathrm{C} 21$ & $2.118(\mathrm{av})$ & $2.122(\mathrm{av})$ & $2.144(\mathrm{av})$ & $\begin{array}{l}2.151(3) \\
/ 2.173(\mathrm{av})\end{array}$ & $2.085(\mathrm{av})$ & $2.099(\mathrm{av})$ & $1.939(2)$ & $1.971(2)$ & $1.914(\mathrm{av})$ & $1.935(2)$ \\
\hline \multicolumn{11}{|c|}{ Angles (deg) } \\
\hline $\mathrm{C} 11-\mathrm{M}-\mathrm{C} 21$ & $99.3(1)$ & $98.6(1)$ & $127.0(1)$ & $\begin{array}{l}106.3(2) / \\
108.9(\mathrm{av})\end{array}$ & $126.7(1)$ & $113.6(1)$ & $90.7(1)$ & $90.4(1)$ & $91.5(1)$ & $89.3(1)$ \\
\hline $\mathrm{N} 1-\mathrm{M}-\mathrm{N} 2$ & $75.7(1)$ & $77.0(1)$ & $73.5(1)$ & $\begin{array}{l}76.9(1) / \\
76.0(\mathrm{av})\end{array}$ & $75.1(2)$ & $77.0(1)$ & $81.6(1)$ & $81.2(1)$ & $81.6(1)$ & $82.1(1)$ \\
\hline $\begin{array}{l}\text { interpyridyl ring torsion } \\
\text { angle }\end{array}$ & 11.3 & 12.7 & 15.2 & $3.2 / 1.2(\mathrm{av})$ & 13.8 & 9.2 & 5.8 & 4.4 & 3.2 & 4.7 \\
\hline $\begin{array}{l}\text { torsion angle } \\
\text { M1,N1,N2/ } \\
\text { M1,C11,C12 }\end{array}$ & 8.1 & 22.7 & 70.6 & $\begin{array}{l}81.9 / \\
82.3(\mathrm{av})\end{array}$ & 70.2 & 78.6 & 22.0 & 4.2 & 12.4 & 5.3 \\
\hline
\end{tabular}
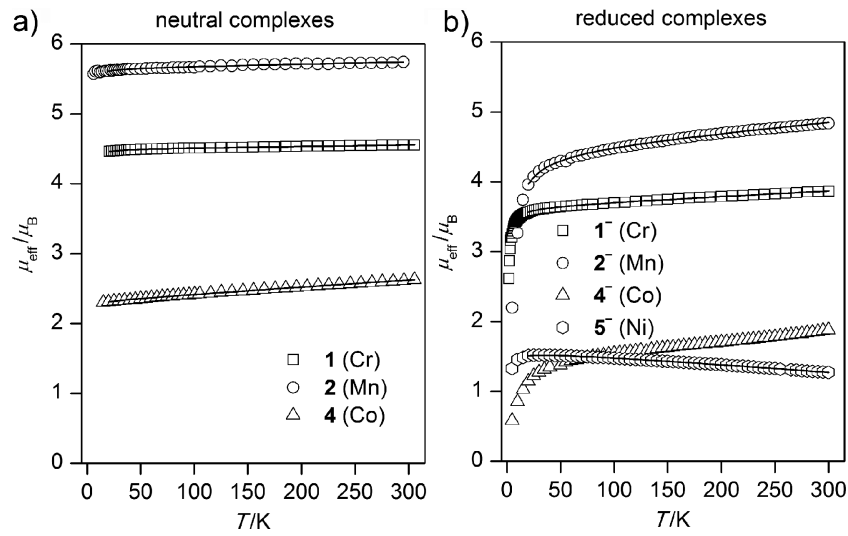

Figure 5. (a) Effective magnetic moments as a function of temperature for (a) complexes 1,2 , and 4 and (b) complexes [K(dibenzo-18-

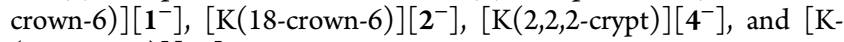
$(2,2,2$-crypt $)]\left[5^{-}\right]$. In each instance the open symbols represent the experimental data and the lines represent the calculated fit.

by contrast, the single vacancy in the low-lying $3 \mathrm{~d}$ manifold is localized in the $\mathrm{d}_{z}{ }^{2}$ orbital, approximately orthogonal to the $\pi^{*}$ orbital of the 2,2'-bipy radical. The orthogonality imposes ferromagnetic coupling, leading to a triplet ground state for $\mathbf{4}_{\mathrm{sp}}{ }^{-}$, the same multiplicity as for $\mathbf{4}_{\mathrm{td}}{ }^{-}$but with a very different electron density distribution. The pseudo-tetrahedral triplet $\mathbf{4}_{\mathrm{td}}{ }^{-}$is computed to be lower in energy than the pseudo-squareplanar isomer, apparently at odds with the X-ray structure, but the separation of only $2 \mathrm{kcal} \mathrm{mol}^{-1}$ to the square-planar triplet $\left(4_{\text {sp }}{ }^{-}\right)$is too small to allow a confident assignment of the ground state. While these calculations do not provide a clear rationale for the unusual magnetic susceptibility of $4^{-}$, it is clear that of all the systems studied this is electronically the most complex, with a number of electronic states with different multiplicities very close to that of the ground state.

The body of data contained in Tables 3 (X-ray) and 5 (DFT) offers a unique opportunity to explore the structural consequences of the interaction between the metal and a neutral or anionic bipyridyl ligand. We note immediately that the $\mathrm{C}(5)-\mathrm{C}(6)$ bond length in the bipyridyl unit is indisputably determined almost entirely by the ligand oxidation state, as proposed by Wieghardt and co-workers: the bond lengths fall into two very narrow bands centered on 1.48 and $1.41 \AA$ for the neutral and anionic derivatives, respectively. ${ }^{15}$ The $\mathrm{M}-\mathrm{N}$ bond lengths, in contrast, show considerable variation across the series. Interpretation of these variations in terms of specific bonding interactions between the $\mathrm{d}$ orbitals and the $\pi^{*}$ orbital of bipy is complicated by the normal periodic variations in ionic radius across the periodic table and also the change in geometry from pseudo-square-planar to pseudotetrahedral, but the $\mathrm{M}-\mathrm{C}$ bond lengths provide a convenient internal reference point. Thus, in either the neutral or anionic tetrahedral pairs $\left(2 / 3\right.$ and $\left.2^{-} / 3^{-}\right)$a decrease of $\sim 0.07 \AA$ in both $\mathrm{M}-\mathrm{N}$ and $\mathrm{M}-\mathrm{C}$ bond lengths on moving from $\mathrm{Mn}$ to $\mathrm{Fe}$ reflects the increase in effective nuclear charge. In contrast, we see that the one-electron reduction of either 2 or 3 causes a $\sim 0.07 \AA$ contraction of $\mathrm{M}-\mathrm{N}$ but only a marginal $(\sim 0.01 \AA)$ elongation of the $\mathrm{M}-\mathrm{C}$ bonds. Similar trends are apparent in the computed structures of $\mathbf{4}_{\mathrm{td}} / \mathbf{4}_{\mathrm{td}}{ }^{-}$, although in this case there 
Table 4. Calculated $g, \Theta$, and $\chi_{\text {TIM }}$ Values for the Neutral and Anionic Complexes Obtained from Fitting the VariableTemperature Magnetic Data of the Complexes to the Curie-Weiss Law ${ }^{a}$

\begin{tabular}{|c|c|c|c|c|c|c|c|}
\hline complex (metal) & mol wt & diamagnetic correction $/ 10^{-4} \mathrm{emu} \mathrm{mol}^{-1}$ & $\mu_{\mathrm{eff}} / \mu_{\mathrm{B}}(300 \mathrm{~K})$ & spin state $S$ & $g$ & $\Theta / \mathrm{K}$ & $\chi_{\mathrm{TIM}} / 10^{-4} \mathrm{emu} \mathrm{mol}^{-1}$ \\
\hline $1(\mathrm{Cr})$ & 446.24 & -2.95 & 4.55 & 2 & 1.84 & -0.4 & 2.3 \\
\hline $2(\mathrm{Mn})$ & 449.18 & -2.94 & 5.74 & $5 / 2$ & 1.91 & -0.3 & 4.7 \\
\hline $3(\mathrm{Fe})$ & 450.09 & -2.93 & 5.12 & 2 & 2.09 & -0.9 & 0.0 \\
\hline $4(\mathrm{Co})$ & 453.17 & -2.92 & 2.62 & $1 / 2$ & 2.67 & -0.4 & 6.4 \\
\hline $\mathbf{1}^{-}(\mathrm{Cr})$ & 845.49 & -5.35 & 3.87 & $|2-1 / 2|=3 / 2$ & 1.88 & -1.0 & 7.4 \\
\hline $2^{-}(\mathrm{Mn})$ & 752.53 & -4.79 & 4.84 & $|5 / 2-1 / 2|=2$ & 1.81 & -5.4 & 19.6 \\
\hline $3^{-}(\mathrm{Fe})$ & 865.44 & -5.60 & 4.98 & $|2-1 / 2|=3 / 2$ & & & \\
\hline $4^{-}(\mathrm{Co})$ & 868.53 & -5.59 & 1.88 & $|1 / 2+1 / 2|=1$ & & & \\
\hline $5^{-}(\mathrm{Ni})$ & 868.29 & -5.59 & 1.27 & $|0-1 / 2|=1 / 2$ & 1.83 & -1.5 & -3.7 \\
\hline
\end{tabular}

${ }^{a}$ Data for 3 from ref 17 .

Table 5. Optimized Geometric and Electronic Parameters for $\left[\mathrm{M}\left(2,2^{\prime}-\mathrm{bipy}\right)(\mathrm{mes})_{2}\right]^{0 /-}(\mathrm{M}=\mathrm{Cr}-\mathrm{Ni}) \mathrm{Complexes}$

\begin{tabular}{|c|c|c|c|c|c|c|c|c|c|c|c|c|}
\hline & \multicolumn{2}{|c|}{$\mathrm{Cr}$} & \multicolumn{2}{|c|}{$\mathrm{Mn}$} & \multicolumn{2}{|c|}{$\mathrm{Fe}$} & \multicolumn{4}{|c|}{ Co } & \multicolumn{2}{|c|}{$\mathrm{Ni}$} \\
\hline & 1 & $1^{-}$ & 2 & $2^{-}$ & 3 & $3^{-}$ & $44_{\text {sp }}$ & $4_{\mathrm{sp}}^{-}$ & $4_{t d}$ & $4_{\mathrm{td}}^{-}$ & 5 & $5^{-}$ \\
\hline$M_{S}{ }^{a}$ & 2 & $3 / 2$ & $5 / 2$ & 2 & 2 & $3 / 2$ & $1 / 2$ & 1 & $3 / 2$ & 1 & 0 & $1 / 2$ \\
\hline$S_{\mathrm{M}} ; S_{\text {bipy }}^{b}$ & $2 ; 0$ & $2 ; 1 / 2$ & $5 / 2 ; 0$ & $5 / 2 ; 1 / 2$ & $2 ; 0$ & $2 ; 1 / 2$ & $1 / 2 ; 0$ & $1 / 2 ; 1 / 2$ & $3 / 2 ; 0$ & $3 / 2 ; 1 / 2$ & $0 ; 0$ & $0 ; 1 / 2$ \\
\hline $\mathrm{M}-\mathrm{N} / \AA \AA$ & 2.19 & 2.14 & 2.22 & 2.19 & 2.20 & 2.13 & 2.04 & 2.02 & 2.12 & 2.07 & 2.01 & 1.99 \\
\hline $\mathrm{M}-\mathrm{C} / \AA ̊ \Omega$ & 2.12 & 2.17 & 2.13 & 2.20 & 2.09 & 2.14 & 1.96 & 1.98 & 2.04 & 2.09 & 1.93 & 1.95 \\
\hline $\mathrm{C}(5)-\mathrm{C}(6) / \AA$ & 1.48 & 1.43 & 1.48 & 1.43 & 1.48 & 1.43 & 1.48 & 1.43 & 1.48 & 1.43 & 1.48 & 1.43 \\
\hline$\Phi^{c} / \operatorname{deg}$ & 18.9 & 20.1 & 63.9 & 75.9 & 67.5 & 73.8 & 17.1 & 17.3 & 69.5 & 74.8 & 17.0 & 16.8 \\
\hline$J^{d} / \mathrm{cm}^{-1}$ & & -508 & & -492 & & -656 & & +396 & & -1050 & & \\
\hline$\left\langle S^{2}\right\rangle$ & 6.05 & 4.69 & 8.84 & 6.89 & 6.05 & 4.62 & 0.78 & 2.03 & 3.80 & 2.80 & 0.00 & 0.76 \\
\hline$\rho_{\mathrm{M}}$ & 4.16 & 4.19 & 4.78 & 4.87 & 3.73 & 3.74 & 1.25 & 1.21 & 2.63 & 2.66 & 0.00 & 0.03 \\
\hline$\rho_{\text {bipy }}$ & & -1.00 & & -0.88 & & -0.86 & & 0.92 & & -0.80 & & 0.98 \\
\hline
\end{tabular}

${ }^{a} M_{S}$ value. ${ }^{b}$ Local spin $S$ on metal and ligand centers. ${ }^{c}$ Defined as the angle between the C11-M-C21 and N3-M-N4 planes. ${ }^{d}$ Coupling constant $J$ calculated using Yamaguchi's formula: $J=-2\left[E_{\mathrm{HS}}-E_{\mathrm{BS}}\right] /\left[S_{\mathrm{HS}}^{2}-S_{\mathrm{BS}}^{2}\right] .^{35}$

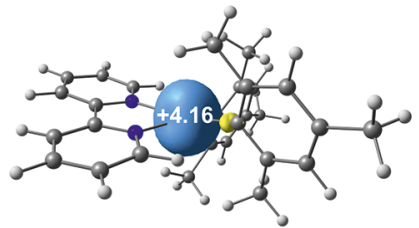

1

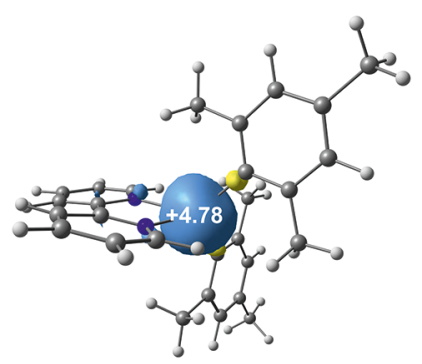

2
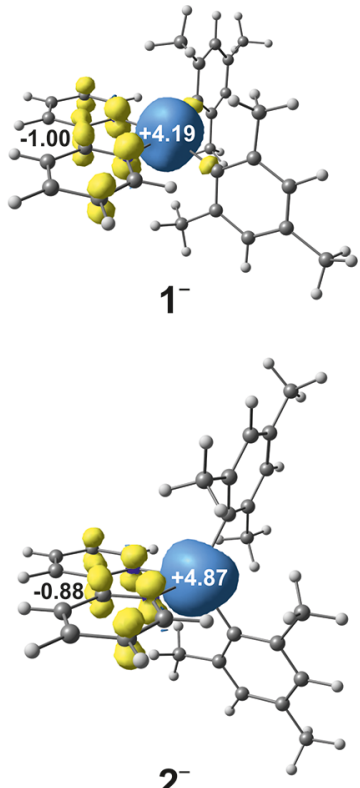

2

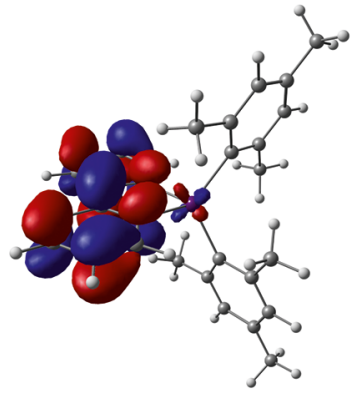

$\mathbf{2}^{-}$

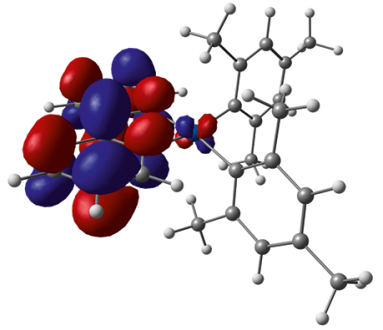

$4_{\mathrm{sp}}{ }^{-}$

Figure 7. Singly occupied spin $\beta$ orbitals in $2^{-}(\mathrm{Mn}-\mathrm{N}$ bonding $)$ and $\mathbf{4}_{\mathrm{sp}}{ }^{-}$( $\mathrm{Co}-\mathrm{N}$ antibonding). In both cases the orbital is composed primarily of bipy $\pi^{*}$, with some residual metal $\mathrm{d}_{x z}$ character.

Turning to the pseudo-square-planar complexes, a contraction of $\mathrm{M}-\mathrm{N}$ relative to $\mathrm{M}-\mathrm{C}$ is apparent in the $1 / 1^{-}$pair, where again the coupling is antiferromagnetic and the bipy $\pi^{*}$ electron has some $\mathrm{M}-\mathrm{N}$ bonding character. For $\mathbf{4}_{\mathrm{sp}}{ }^{-}$and $\mathbf{5}^{-}$ the coupling is either ferromagnetic $\left(4_{\mathrm{sp}}{ }^{-}\right)$or zero $\left(5^{-}\right)$, because the overlapping metal-based $\mathrm{d}$ orbital is doubly occupied, and so the singly occupied spin $\beta$ orbital has $\mathrm{M}-\mathrm{N}$ antibonding character. As a result, the redox-induced changes in $\mathrm{M}-\mathrm{N}$ bond lengths in $\mathbf{4}$ and $\mathbf{5}$ are much smaller and are less distinct from the changes in $\mathrm{M}-\mathrm{C}$. Before leaving the question of the relationship between structure and bonding, we can make one further observation on the controversial issue of back-bonding in the metal bipyridyl. Our analysis set out above supports the proposal that changes in back-bonding across this 
entire series, whether neutral or anionic, are limited, or at least have minimal impact on bond metrics. The periodic variations in $\mathrm{M}-\mathrm{N}$ and $\mathrm{M}-\mathrm{C}$ bond lengths appear entirely understandable in the framework of trends in ionic radius superimposed on a small degree of delocalization of the electron in the bipy $\pi^{*}$ orbital, where present. In the course of our survey of the potential energy surface of $4^{-}$, we have also located a closed-shell singlet state, ${ }^{\mathbf{1}} \mathbf{4}^{-}$, which is isoelectronic and isostructural with the neutral nickel complex 5. The spinrestricted nature of the calculation means that this species can be formulated unambiguously as a $\mathrm{d}^{8} \mathrm{Co}(\mathrm{I})$ center coordinated to a neutral bipy ligand. ${ }^{1} \mathbf{4}^{-}$is almost $20 \mathrm{kcal} \mathrm{mol}^{-1}$ higher in energy than the triplet ground state and so is clearly not relevant to the interpretation of the structural or magnetic data. Nevertheless, the rather short $\mathrm{C}(5)-\mathrm{C}(6)$ bond length of 1.44 $\AA$ (full details in the Supporting Information) in comparison to $1.48 \AA$ in 5 confirms that conventional back-bonding of a pair of metal-based electrons can have a structural impact on the $\mathrm{C}-$ $\mathrm{C}$ bond of bipyridyl in cases where the metal center is extremely electron rich. It seems unlikely, however, that such a system will be realizable experimentally, because in cases where the metal is sufficiently electron rich to afford strong backbonding, electron transfer to form a bipy ${ }^{-}$radical will be even more favorable, as it is in $4^{-}$.

Our research has shown that transition-metal complexes featuring anionic radical ligands are readily accessible via the chemical reduction of their neutral parent compounds. Furthermore, it appears that bond metric data in the bipyridyl moiety can be used as strong indicators of the charge associated with the ligand, although subtle fluctuations in $\mathrm{M}-\mathrm{N}$ and $\mathrm{M}-\mathrm{C}$ bonds are complementary to the magnetic measurements in offering insights into the nature of the interaction between metal and ligand. To date there have been several high-profile publications in the chemical literature in which metal centers are bridged by radical ligands (for the synthesis of solids with interesting magnetic properties). ${ }^{36}$ The results detailed in this paper may provide a route toward such materials; our research groups have already begun related studies on the bridging $4,4^{\prime}$ bipyridine isomer and its radical and dianionic congeners. ${ }^{37}$

\section{ASSOCIATED CONTENT}

\section{S Supporting Information}

Figures, text, tables, and CIF files giving X-ray crystallographic data for all complexes, detailed synthesis of [Cr$\left.\left(\mathrm{PMe}_{3}\right)_{2}(\mathrm{mes})_{2}\right]$, PXRD data, IR, Raman, and EPR spectra, computational details, and magnetic data. This material is available free of charge via the Internet at http://pubs.acs.org.

\section{AUTHOR INFORMATION}

\section{Corresponding Author}

*E-mail: john.mcgrady@chem.ox.ac.uk (J.E.M.); jose. goicoechea@chem.ox.ac.uk (J.M.G.).

\section{Notes}

The authors declare no competing financial interest.

\section{ACKNOWLEDGMENTS}

We thank the EPSRC and the University of Oxford (studentships to M.I. and T.K.) for financial support of this research. We also thank Steve Boyer (London Metropolitan University) for performing all elemental analyses and the Oxford Crystallographic Service, the Oxford Supercomputing Centre, and CAESR for access to instrumentation. R.H. thanks the Operational Program Research and Development for Innovations (CZ.1.05/2.1.00/03.0058) of the Ministry of Education, Youth and Sports of the Czech Republic. Finally, we also thank Diamond Light Source for beam time on I19 (MT1858) used for data collection on sample $2 \mathrm{a}^{-}$.

\section{REFERENCES}

(1) Comprehensive reviews of the early coordination chemistry of 2,2'-bipyridine and its redox chemistry are available in: (a) Creutz, C. Comments Inorg. Chem. 1982, 1, 293. (b) Constable, E. C. Homoleptic Complexes of 2,2'-Bipyridine. In Advances in Inorganic Chemistry; Sykes, A. G., Ed.; Academic Press: San Diego, CA, 1989; Vol. 34, p 1.

(2) UV spectroscopy: (a) König, E.; Herzog, S. J. Inorg. Nucl. Chem 1970, 32, 585. (b) König, E.; Kremer, S. Chem. Phys. Lett. 1970, 5, 87. (c) Mahon, C.; Reynolds, W. L. Inorg. Chem. 1967, 6, 1927.

(3) IR spectroscopy: Saito, Y.; Takemoto, J.; Hutchinson, B.; Nakamoto, K. Inorg. Chem. 1972, 11, 2003.

(4) Raman spectroscopy: (a) Kawashima, H.; Kato, T.; Shida, T. J. Raman Spectrosc. 1991, 22, 187. (b) Castellà-Ventura, M.; Kassab, E.; Buntinx, G.; Poizat, O. Phys. Chem. Chem. Phys. 2000, 2, 4682. (c) Danzer, G. D.; Golus, J. A.; Strommen, D. P.; Kincaid, J. R. J. Raman Spectrosc. 1990, 21, 3. (d) Bradley, P. G.; Kress, N.; Hornberger, B. A.; Dallinger, R. F.; Woodruff, W. H. J. Am. Chem. Soc. 1981, 103, 7441.

(5) EPR spectroscopy: (a) Zahlan, A.; Heineken, F. W.; Bruin, M.; Bruin, F. J. Chem. Phys. 1962, 37, 683. (b) Dos Santos-Veiga, J.; Reynolds, W. L.; Bolton, J. R. J. Chem. Phys. 1966, 44, 2214. (c) Henning, J. C. M. J. Chem. Phys. 1966, 44, 2139. (d) Van Voorst, J. D. W.; Zijlstra, W. G.; Sitters, R. Chem. Phys. Lett. 1967, 1, 321. (e) König, E.; Fischer, H. Z. Naturforsch. 1962, 17a, 1063. (f) Kaim, W. Chem. Ber. 1981, 114, 3789. (g) Herzog, S.; Gustav, K. Z. Anorg. Allg. Chem. 1966, 346, 150. (h) Wulf, E.; Herzog, S. Z. Anorg. Allg. Chem. 1972, 387, 81. (i) Herzog, S.; Taube, R. Z. Chem. 1962, 2, 208. (j) Herzog, S.; Lühder, K. Z. Chem. 1966, 6, 475. (k) Kaim, W.; Lubitz, W. Angew. Chem., Int. Ed. Engl. 1983, 22, 892.

(6) Chisholm, M. H.; Huffman, J. C.; Rothwell, I. P.; Bradley, P. G.; Kress, N.; Woodruff, W. H. J. Am. Chem. Soc. 1981, 103, 4945.

(7) Gore-Randall, E.; Irwin, M.; Denning, M. S.; Goicoechea, J. M. Inorg. Chem. 2009, 48, 8304.

(8) Bock, H.; Lehn, J.-M.; Pauls, J.; Holl, S.; Krenzel, V. Angew. Chem., Int. Ed. 1999, 38, 952.

(9) (a) Bellavance, P. L.; Corey, E. R.; Corey, J. Y.; Hey, G. W. Inorg. Chem. 1977, 16, 462. (b) Nikiforov, G. B.; Roesky, H. W.; Noltemeyer, M.; Schmidt, H.-G. Polyhedron 2004, 23, 561. (c) Mansell, S. M; Adams, C. J.; Bramham, G.; Haddow, M. F.; Kaim, W.; Norman, N. C.; McGrady, J. E.; Russell, C. A.; Udeen, S. J. Chem. Commun. 2010, 46, 5070. (d) Mansell, S. M.; Norman, N. C.; Russell, C. A. Dalton Trans. 2010, 39, 5084.

(10) (a) Evans, W. J.; Drummond, D. K. J. Am. Chem. Soc. 1989, 111, 3329. (b) Evans, W. J.; Gonzales, S. L.; Ziller, J. W. J. Am. Chem. Soc. 1994, 116, 2600. (c) Schultz, M.; Boncella, J. M.; Berg, D. J.; Tilley, T. D.; Andersen, R. A. Organometallics 2002, 21, 460. (d) Roitershtein, D.; Domingos, A.; Pereira, L. C. J.; Ascenso, J. R.; Marques, N. Inorg. Chem. 2003, 42, 7666. (e) Walter, M. D.; Berg, D. J.; Andersen, R. A Organometallics 2006, 25, 3228. (f) Booth, C. H.; Walter, M. D.; Kazhdan, D.; Hu, Y.-J.; Lukens, W. W.; Bauer, E. D.; Maron, L.; Eisenstein, O.; Andersen, R. A. J. Am. Chem. Soc. 2009, 131, 6480. (g) Williams, B. N.; Huang, W.; Miller, K. L.; Diaconescu, P. L. Inorg. Chem. 2010, 49, 11493.

(11) (a) Wiley, R. O.; Von Dreele, R. B.; Brown, T. M. Inorg. Chem. 1980, 19, 3351. (b) Kraft, S. J.; Fanwick, P. E.; Bart, S. C. Inorg. Chem. 2010, 49, 1103. (c) Ren, W.; Zi, G.; Walter, M. D. Organometallics 2012, 31, 672.

(12) (a) Kaizu, Y.; Kobayashi, H. Bull. Chem. Soc. Jpn. 1970, 43, 2492. (b) Kaizu, Y.; Kobayashi, H. Bull. Chem. Soc. Jpn. 1972, 45, 470. (c) Vlček, A.; Baumann, F.; Kaim, W.; Grevels, F.-W.; Hartl, F. J. Chem. Soc., Dalton Trans. 1998, 215. (d) Zálišs, S.; Daniel, C.; Vlček, A. J. Chem. Soc., Dalton Trans. 1999, 3081. 
(13) (a) McPherson, A. M; Fieselmann, B. F.; Lichtenberger, D. L.; McPherson, G. L.; Stucky, G. D. J. Am. Chem. Soc. 1979, 101, 3425. (b) Radonovich, L. J.; Eyring, M. W.; Groshens, T. J.; Klabunde, K. J. J. Am. Chem. Soc. 1982, 104, 2816. (c) Pérez-Cordero, E. E.; Campana, C.; Echegoyen, L. Angew. Chem., Int. Ed. 1997, 36, 137. (d) Rosa, P.; Mézailles, N.; Richard, L.; Mathey, F.; Le Floch, P. Angew. Chem., Int. Ed. 2000, 39, 1823. (e) Mork, B. V.; McMillan, A.; Yuen, H.; Tilley, T. D. Organometallics 2004, 23, 2855.

(14) Lenges, C. P.; White, P. S.; Marshall, W. J.; Brookhart, M. Organometallics 2000, 19, 1247.

(15) (a) Scarborough, C. C.; Wieghardt, K. Inorg. Chem. 2011, 50, 9773. (b) Scarborough, C. C.; Sproules, S.; Weyhermüller, T.; DeBeer, S.; Wieghardt, K. Inorg. Chem. 2011, 50, 12446. (c) Bowman, A. C.; Sproules, S.; Wieghardt, K. Inorg. Chem. 2012, 51, 3707.

(16) Dieck, T.; Franz, K.-D.; Hohmann, F. Chem. Ber. 1975, 108, 163.

(17) Irwin, M.; Jenkins, R. K.; Denning, M. S.; Krämer, T; Grandjean, F; Long, G. J.; Herchel, R; McGrady, J. E.; Goicoechea, J. M. Inorg. Chem. 2010, 49, 6160.

(18) Hermes, A. R.; Morris, R. J.; Girolami, G. S. Organometallics 1988, 7, 2372

(19) Solari, E.; Musso, F.; Gallo, E.; Floriani, C.; Re, N.; Chiesi-Villa, A.; Rizzoli, C. Organometallics 1995, 14, 2265.

(20) Chatt, J.; Shaw, B. L. J. Chem. Soc. 1961, 285.

(21) Klein, A. Z. Anorg. Allg. Chem. 2001, 627, 645.

(22) (a) Tsutsui, M.; Zeiss, H. J. Am. Chem. Soc. 1960, 82, 6255. (b) Stolze, G.; Hahle, J. J. Organomet. Chem. 1967, 7, 301. (c) Edema, J. J. H.; Gambarotta, S.; van Bolhuis, F.; Smeets, W. J. J.; Spek, A. L.; Chiang, M. Y. J. Organomet. Chem. 1990, 389, 47.

(23) Cosier, J.; Glazer, A. M. J. Appl. Crystallogr. 1986, 19, 105.

(24) Otwinowski, Z.; Minor, W. Processing of X-ray Diffraction Data Collected in Oscillation Mode. In Methods in Enzymolology; Academic Press: New York, 1997.

(25) CrystalClear-SM Expert 2.0 r4; Rigaku, Tokyo, Japan, 2009.

(26) (a) Sheldrick, G. M. Acta Crystallogr. 1990, A46, 467. (b) Sheldrick, G. M. SHELX97-Programs for Crystal Structure Analysis (Release 97-2); Institut für Anorganische Chemie der Universität, Tammanstrasse 4, D-3400 Göttingen, Germany, 1998. (c) Sheldrick, G. M. Acta Crystallogr. 2008, A64, 112.

(27) Bain, G. A.; Berry, J. F. J. Chem. Educ. 2008, 85, 532.

(28) Neese, F. ORCA-an $a b$ initio, density functional and semiempirical program package, version 2.6, revision 35; University of Bonn, Bonn, Germany, Feb 2008 (http://www.thch.uni-bonn.de/tc/orca/).

(29) (a) Becke, A. D. J. Chem. Phys. 1993, 98, 5648. (b) Stephens, P. J.; Devlin, J. F.; Chabalowski, C. F.; Frisch, M. J. J. Phys. Chem. 1994, 98, 11623. (c) Lee, C. T.; Yang, W. T.; Parr, R. G. Phys. Rev. B 1988, 37, 785 .

(30) Schäfer, A.; Huber, C; Ahlrichs, R. J. Chem. Phys. 1994, 100, 5829 .

(31) Schäfer, A.; Horn, H.; Ahlrichs, R. J. Chem. Phys. 1992, 97, 2571.

(32) Ghosh, M.; Sproules, S.; Weyhermüller, T.; Wieghardt, K. Inorg. Chem. 2008, 47, 5963.

(33) See for example: (a) Soda, T.; Kitagawa, Y.; Onishi, T.; Takano, Y.; Shigeta, Y.; Nagao, H.; Yoshioka, Y.; Yamaguchi, K. Chem. Phys. Lett. 2000, 319, 223. (b) Lu, C. C.; Bill, E.; Weyhermüller, T.; Bothe, E.; Wieghardt, K. J. Am. Chem. Soc. 2008, 130, 3181. (c) Chatt, J; Shaw, B. L. J. Chem. Soc. 1961, 285. (d) Cibian, M.; Derossi, S.; Hanan, G. S. Dalton Trans. 2011, 40, 1038.

(34) Szabo, A.; Ostlund, N. S. Modern Quantum Chemistry: Introduction to Advanced Electronic Structure Theory; Dover: New York, 1996.

(35) Yamaguchi, K.; Takahara, Y.; Fueno, T. In Applied Quantum Chemistry, Smith, V. H., Ed.; Reidel: Dordrecht, The Netherlands, 1986; p 155.

(36) For recent reviews see: (a) Dechambenoit, P.; Long, J. R. Chem. Soc. Rev. 2011, 40, 3249. (b) Murray, K. Aust. J. Chem. 2009, 62, 1081.

(37) (a) Irwin, M; Krämer, T; McGrady, J. E.; Goicoechea, J. M.

Inorg. Chem. 2011, 50, 5006. (b) Denning, M. S.; Irwin, M.; Goicoechea, J. M. Inorg. Chem. 2008, 47, 6118.

\section{NOTE ADDED AFTER ASAP PUBLICATION}

Due to a production error, this paper was published on the Web on October 30, 2012, with formatting errors. The corrected version was reposted on October 31, 2012. 